Miguel Ángel

Anibarro y Esther Valdés

\section{Fascinante y detestable Artelización e integración de los paisajes industriales}

Palabras clave: Paisaje industrial, patrimonio industrial, percepción, arte, territorio.

Uno de los ejemplos más controvertidos del uso del término paisaje se refiere al de los de tipo industrial, al estar formados por complicadas instalaciones de todo tipo, incluyendo ahora también elementos como gigantescos aerogeneradores o extensos huertos solares. De lo que se trata es de indagar si es posible y cuando se produce una consideración estética de tales instalaciones comprendidas en su entorno, especialmente si es campestre. Se hace uso para ello del concepto de "artelización" introducido por Alain Roger y de una nítida diferenciación entre paisaje y territorio. Pero también se advierte de que no siempre se logra esa apreciación estética y que con frecuencia se asiste a situaciones calificables como "despaisajes". Un recorrido por una escogida selección de ejemplos permite abordar sus casos más característicos y aproximarse a una categorización de los mismos.
Si tuviéramos que describir con pocas palabras el proceso por el que un sujeto (ya sea individuo o sociedad) avanza en la asimilación de un paisaje, lo hariamos distinguiendo tres momentos: la mirada induce, primero, a contemplar el paisaje y luego a reconocerlo; el reconocimiento provoca la emoción y después la reflexión que, al preguntarse por lo percibido, permite entenderlo; por fin la comprensión del paisaje lleva a estimarlo y, en los mejores casos, a un sentimiento de empatía con la realidad que en él se manifiesta. Esta progresión puede durar minutos o siglos y depende tanto del entorno como del ojo que mira. Así ha ocurrido de forma paulatina en el devenir de la historia, y así está ocurriendo en los últimos decenios de un modo que nos parece mucho más veloz.

Ahora bien, al tiempo que continúa este proceso, en el presente el término paisaje se aplica a cuanto nos rodea sin preguntarse por sus rasgos y sus cualidades, como si sólo se precisara cumplir unos mínimos relativos a la escala y a algún aspecto cultural o estético. De este modo la idea de paisaje se convierte en un cajón de sastre donde caben tanto usos inconscientemente metafóricos como otros declaradamente distorsionados. Quizá convenga detenerse de vez en cuando con el fin evitar que, ampliándolo tanto, el concepto acabe por desvirtuarse. A este respecto, uno de los ejemplos más controvertidos es el de los paisajes industriales, formados por complicadas instalaciones de naves, maquinaria y tuberias, polvorientas minas a cielo abierto, gigantescos aerogeneradores de perfil estilizado, escultóricas chimeneas humeantes o extensiones amorfas de huertos solares, que se han convertido en protagonistas frecuentes de nuestros panoramas.
Pues bien, podemos hablar de paisajes industriales -incluyendo en ellos, a estos efectos, los mineros y los energéticos- no para referirnos a los modos de ocupación de un territorio, a la explotación de sus recursos naturales o a sus efectos medioambientales, sino cuando se produce una consideración estética de tales instalaciones comprendidas en su entorno, especialmente si éste es campestre. Es decir, cuando las observamos como configuraciones complejas combinadas con los elementos de la naturaleza, susceptibles de ser no sólo percibidas, sino experimentadas con algún grado de satisfacción estética.

Enseguida habrá surgido en la mente del lector el escollo principal que esta consideración plantea: dadas sus características, ¿puede un complejo industrial apreciarse de este modo? Parece claro que, al ritmo acelerado con que la tecnología permite construirlos, nos hemos ido acostumbrando a observar estos artefactos con el convencimiento de que su presencia forma parte del progreso y el bienestar de nuestra sociedad, como si fuera un hecho ineluctable, aún si nos domina la convicción de que, en general, poco placer puede obtenerse de su contemplación. Es habitual, en el caso de las instalaciones más agresivas, admitir su necesidad económica pero rechazar su presencia en la proximidad de nuestro hábitat: una actitud frecuentemente calificada de hipócrita.

\section{Paisaje-imagen y paisaje-forma}

Augustin Berque y Alain Roger han puesto de manifiesto el proceso por el cual se constituye el concepto de paisaje. Berque (1995: 34s., 2009: 60) estableció algunos criterios que permiten reconocer una cul- 

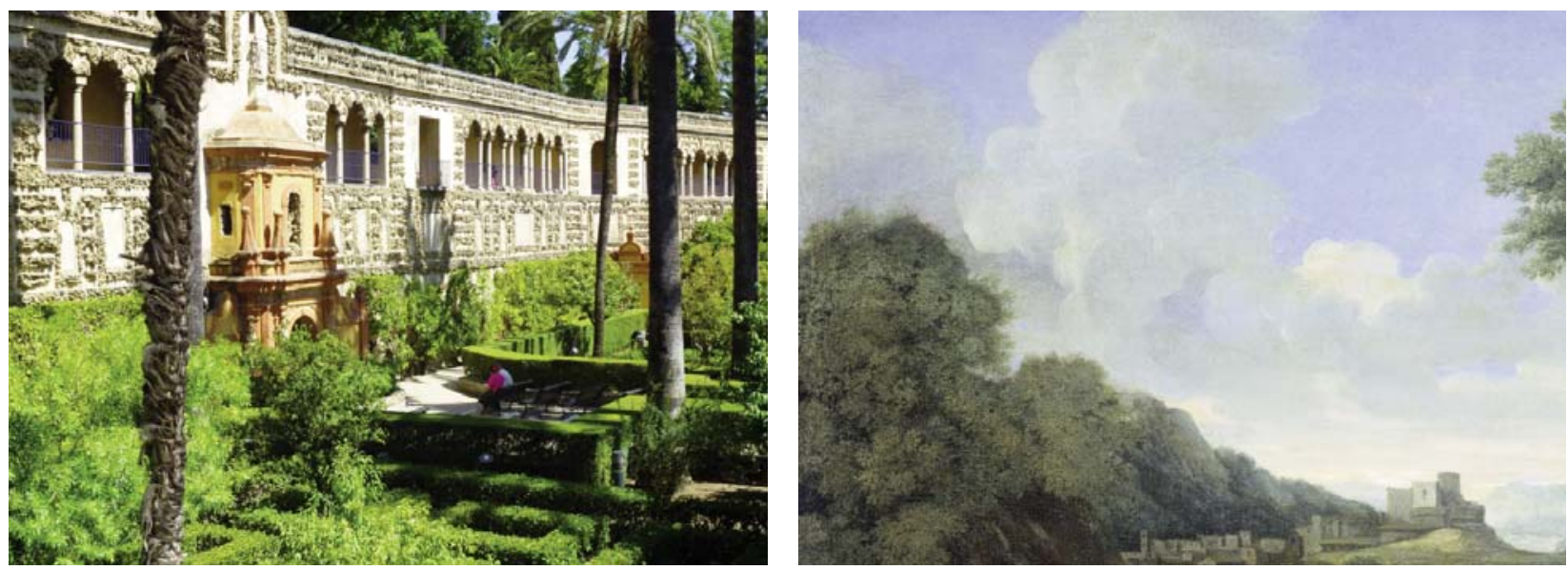

Izquierda. Figura 1. Jardines de los Reales Alcázares de Sevilla. Fuente: autores.

Derecha. Figura 2. Gaspard Dughet,

Paisaje, óleo sobre lienzo, 1640-45,

Rijksmuseum. Fuente: ref. web 1.

Figura 3. Utagawa Hiroshige, Chubasco repentino sobre Shogo, 1833. Fuente: ref. web 2. tura paisajista, mientras Roger (2007: 21ss.) identificó la progresiva asimilación cultural del paisaje con el neologismo 'artelización', distinguiendo entre una artelización directa, en el sitio, y otra indirecta, en la imagen ${ }^{1}$ (figuras 1 y 2). Sobre estas bases es posible rastrear en las culturas históricas (al menos en la occidental y en la china) tanto las interpretaciones del paisaje producidas con la mediación de las artes, como la aprehensión progresiva de paisajes específicos (montes, mar, selvas, desiertos etc.) en el imaginario colectivo mediante acuerdos sociales implícitos.

Así pues, el concepto de paisaje nos habla tanto de su dimensión física como de la cultural. No ha sido construido sólo como imagen, a partir de la percepción del observador, sino que identifica una forma material cuyos rasgos concretos dependen del relieve y composición del terreno, del discurrir de las aguas en él, de la interacción de los componentes bióticos (vegetales y animales), de los fenómenos atmosféricos ligados al clima y de la acción antrópica en el transcurso de la historia. La mirada dirigida a esta configuración implica, de darse, su apreciación estética, de la cual derivan su representación artística y un orden nuevo de significados añadidos a los existentes antes de su consideración como paisaje. Tetsuro Watsuji (2006) llamó la

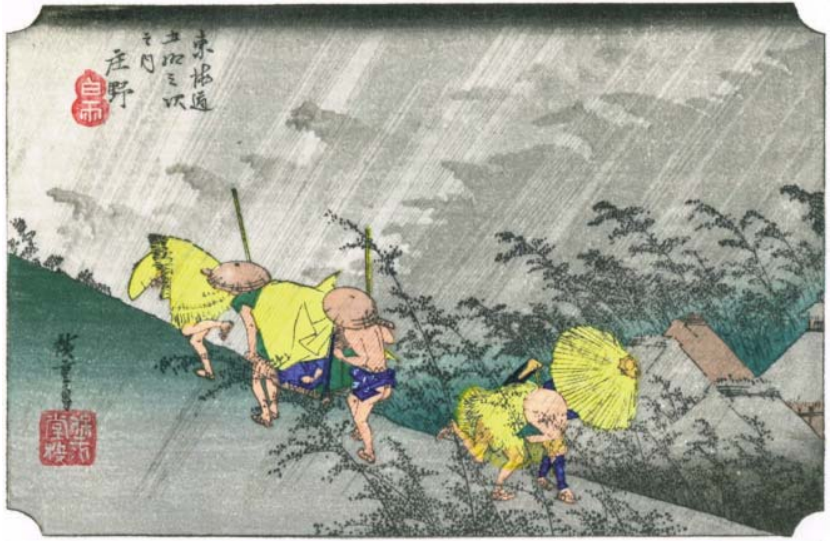

atención sobre la unidad esencial de todos estos factores, en particular sobre la interrelación de clima, paisaje y cultura en el mundo oriental (figura 3); y Berque (2009: $81 \mathrm{~s}$.) advirtió sobre la contraposición entre la mirada subjetiva y la forma objetiva hacia la que se dirige -aspectos de un mismo fenómeno- y la necesidad de alcanzar un enfoque sintético que permita dar cuenta del paisaje como una realidad compleja.

Ahora bien, esta reclamación nada tiene que ver con una reducción del paisaje al territorio o al medio ambiente. Eduardo Martínez de Pisón (2007) ha distinguido paisaje y territorio asignando al primero los factores de forma, percepción, representación y significado, y al segundo los de ocupación, explotación y uso (con sus propios significados adheridos) (figura 4). El deslizamiento que tiende a confundir paisaje con territorio suele ir acompañado de la desvalorización de los atributos estéticos en favor de los geográficos. Pero también es frecuente incurrir en otra reducción que vincula el paisaje exclusivamente a sus aspectos pictóricos, dejándolo anclado en la visión romántica de dos siglos atrás. Consideramos fundamental no caer en ninguno de los dos errores: tan grave es vaciar el concepto de los contenidos que permiten al individuo gozar de la experiencia estética del paisaje, como negarle otros valores que le permitan empatizar con el entorno del que forma parte. Entendemos que ambas posturas no solo son compatibles sino que se complementan y retroalimentan. Además, junto a los estéticos y territoriales hay que añadir los factores medioambientales, que responden a una lógica distinta no siempre conciliable con la del paisaje. Por tanto, procuraremos referirnos al paisaje con el enfoque unitario que permite considerarlo como una realidad compuesta -simultáneamente objetiva y subjetiva-, diferenciándolo de los aspectos territoriales y medioambientales, 

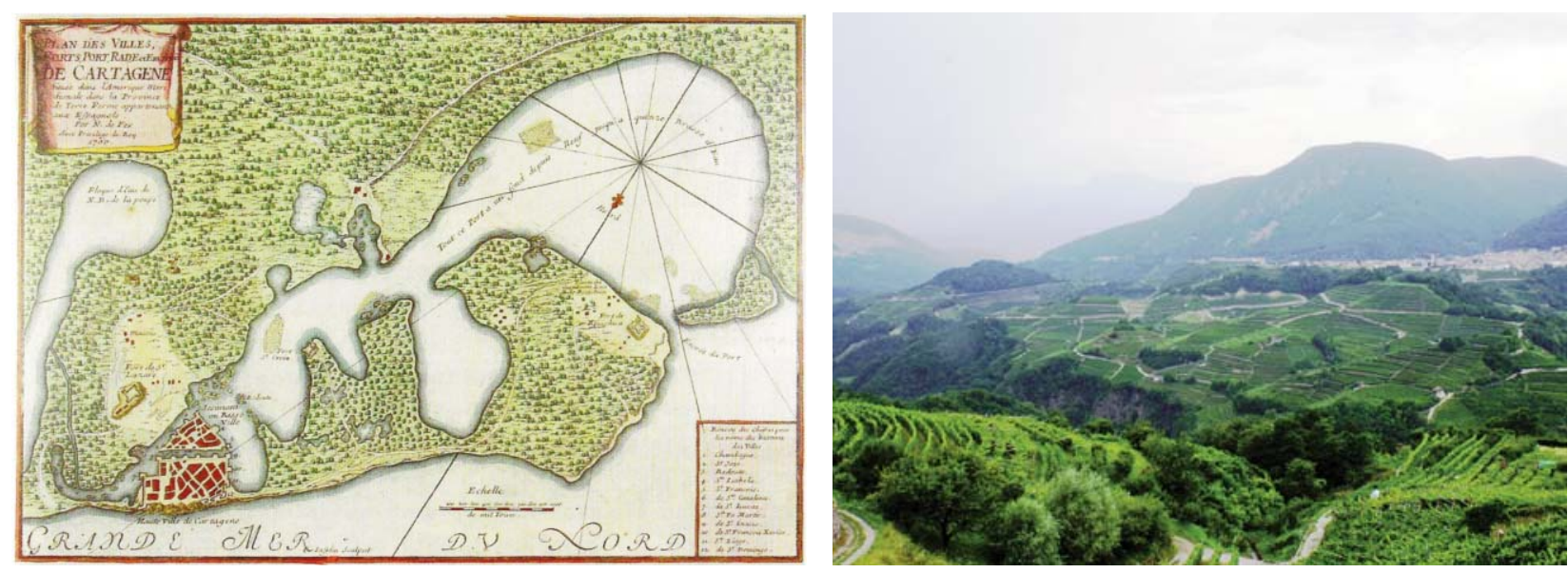

Izquierda. Figura 4. Joaquin Fidalgo,

Bahía de Cartagena de Indias, plano topográfico, 1778. Fuente: Rodolfo Segovia. 2009. The

Fortifications of Cartagena de Indias. Bogotá: Ancora.

Derecha. Figura 5. Paisaje de viñedos en la región italiana del Trentino-Alto Adige, Italia. Fuente: autores.

Figura 6. Centuriatio romana aún visible en los alrededores de Crevalcore, provincia de Bolonia. Fuente: ref. web 3. e intentando no caer en el reduccionismo pictórico.

Sin embargo, lejos de ser una realidad permanente, el paisaje está en cambio constante como resultado de fenómenos naturales, ya sean prolongados y continuos (erosiones, evolución de las especies) o instantáneos y violentos (terremotos, erupciones, inundaciones). Pero también la intervención humana es capaz de introducir modificaciones locales de notable intensidad y extensión, tanto mediante los cultivos agrícolas, que han transformado la faz de la tierra durante milenios (figura 5), la construcción de artefactos (santuarios, ciudades u obras públicas) y la explotación de recursos (mineros, industriales y energéticos), como por decisiones administrativas de ordenación territorial de largo alcance (la centuriatio romana (figura 6), la Land Ordinance en Estados Unidos); esto dejando aparte los accidentes y las acciones intencionadas de violencia extrema: incendios, lluvia ácida, explosiones nucleares, ataques militares con napalm. Así pues, por una parte la idea o imagen mental del paisaje se constituye progresivamente en periodos largos de varios siglos de duración y en paralelo con el descubrimiento de paisajes específicos, que en nuestra cultura todavía continúa; por otra, el paisaje-forma es producto de una evolución debida a la acción de la naturaleza y la acción de los seres humanos combinadas en procesos morfogenéticos permanentes que, por lo que concierne a la segunda, se producen actualmente de manera acelerada.

\section{Despaisajes contemporáneos}

Hariamos bien en tener en cuenta estas consideraciones al abordar el problema de aquellos paisajes contemporáneos cuyos atributos formales han sido modificados, a veces degradados o consumidos, por expansiones suburbanas, instalaciones industriales e infraestructuras de transporte, y también por el abandono de las mismas. Ciertamente estos casos no son iguales en sus efectos estético-paisajísticos, en su soporte social y económico ni en su impacto ecológico, ni tienen porqué ser considerados a priori negativamente: baste recordar ejemplos tan distintos como el puente de Salginatobel en Suiza, de Robert Maillart (figura 7), o los laboratorios de

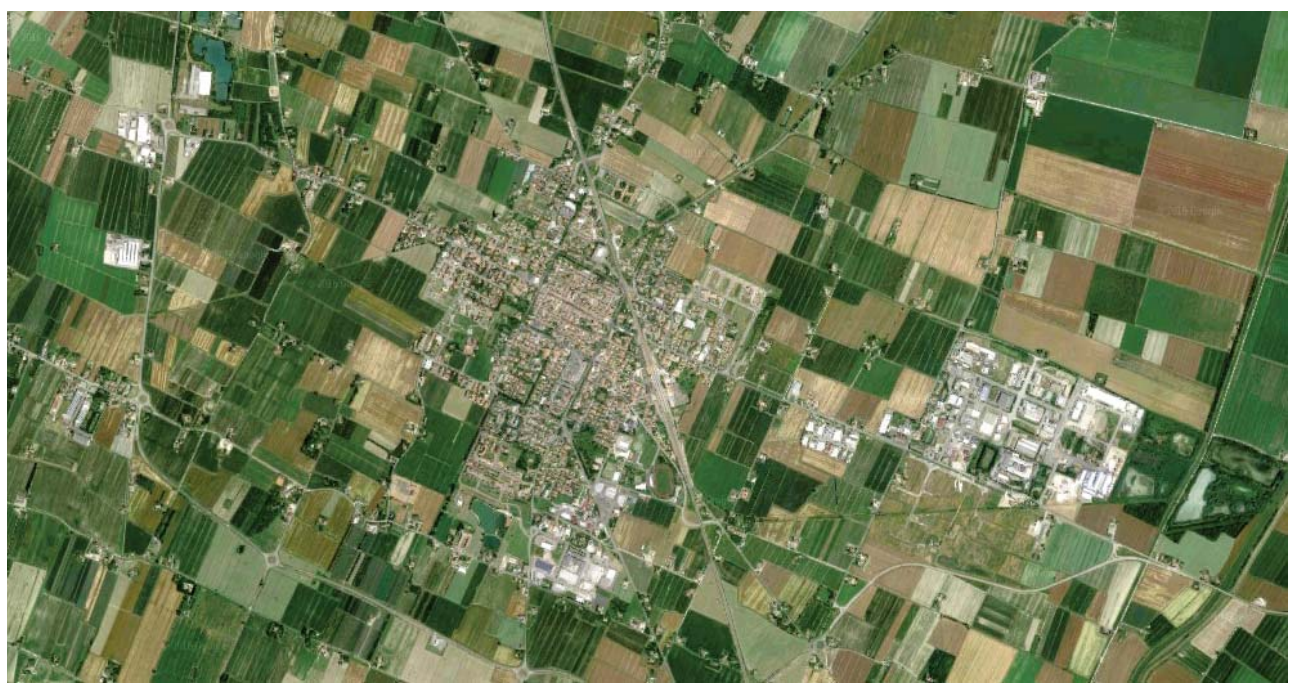


Figura 7. Robert Maillart, puente de Salginatobel (Suiza), 1930. Fuente: ref. web 4.

Figura 8. Residuos tóxicos en la bahía de Portmán (Murcia). Fuente: autores.

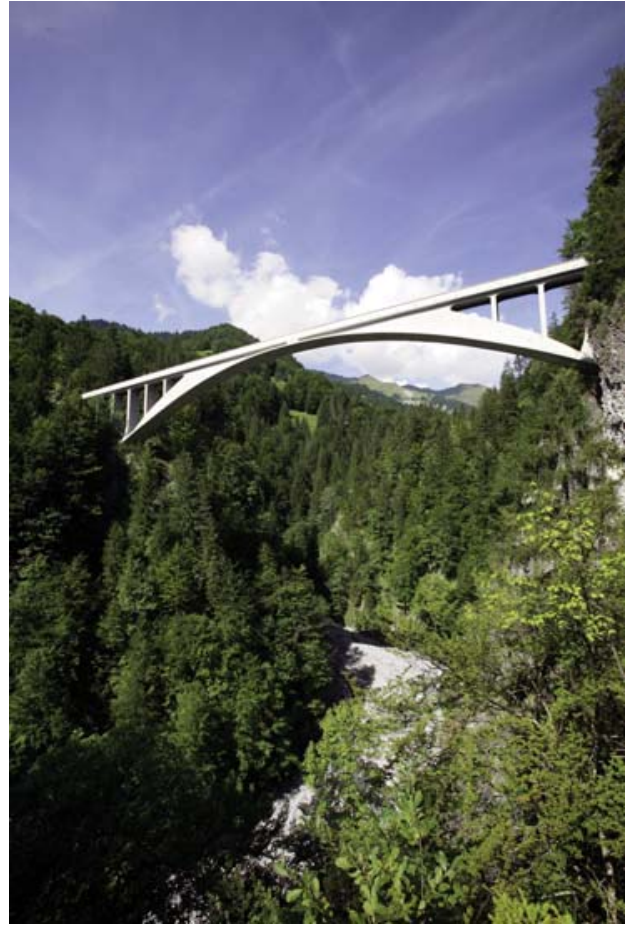

altas energias de Rutherford en Harwell, Inglaterra, de Geoffrey Jellicoe. Pero muy frecuentemente, al planificarlos, su integración en el entorno no ha sido motivo de especial preocupación. La consecuencia es una pérdida del paisaje que podemos designar con otro neologismo: 'despaisaje'. Trasladando el término al terreno que seguramente le es más propio, ${ }^{2}$ llamaremos aquí despaisaje a aquella situación en que las cualidades específicas de un paisaje han sido trastocadas en aspectos esenciales o destruidas, bien sea por la acción humana o de la naturaleza, en periodos relativamente cortos de tiempo, sin que ulteriores procesos de actuación o de asimilación hayan permitido reconfigurarlo como paisaje o reconsiderarlo con nuevos valores paisajísticos (figura 8). ${ }^{3}$

Pues bien, las consideraciones anteriores deberian prevenirnos ante la suposición de que cualquier operación de ocupación, aprovechamiento o explotación territorial acabará siendo asimilada como paisaje a través del proceso de artelización correspondiente, con independencia de su calidad formal y de su adaptación al entorno. O ante la pretensión de forzar el proceso social de asimilación cultural mediante el fomento interesado de su representación artística, con objeto de modificar la percepción colectiva de actuaciones que implican pérdida de las cualidades estéticas constitutivas de un paisaje. Los fenómenos de artelización se caracterizan por un transcurso lento e inconsciente en los planos social e individual; el que a través de los medios audiovisuales sean ahora más veloces y más frecuentes que en el pasado, y que algunos muy significativos se dirijan precisamente hacia entornos desolados los hace susceptibles de manipulación, introduciendo una dimensión moral que no estaba presente de este modo en otras épocas. ¿Sería lícita la manipulación de la conciencia colectiva a través de los lenguajes artísticos con el fin de que ciertos despaisajes, resultado de intereses nada respetuosos con su entorno, sean aceptados como culturalmente relevantes?

A este respecto hay que hacer notar que los procesos conocidos de asimilación de paisajes en las Edades Moderna y Contemporánea, que comenzaron con los campos cultivados inmediatos a las poblaciones, atañeron después a paisajes con un grado de antropización muy escaso: la alta montaña, el mar y sus orillas, los bosques, más adelante las selvas, el desierto y las regiones heladas de los polos. Pero en el último medio siglo, al tiempo que proseguian los descubrimientos y cambiaba su indole por intermediación de los avances técnicos (paisajes submarinos, aéreos y planetarios), se ha empezado a producir la artelización de paisajes degradados por una acción intensa y no controlada del hombre. El land art norteamericano se dirige tanto a los ámbitos desolados de desiertos y lagos salados o secos como a los expoliados por las infraestructuras o la 
Izquierda. Figura 9. Jean Foutrier, Sarah, Empastes con blanco de plomo, óleo y pastel sobre papel montado sobre lienzo, 1943, Museo Nacional Centro de Arte Reina Sofia. Fuente: ref. web 5.

Derecha. Figura 10. Corte del terreno en la mina de Riotinto (Huelva). Fuente: autores.

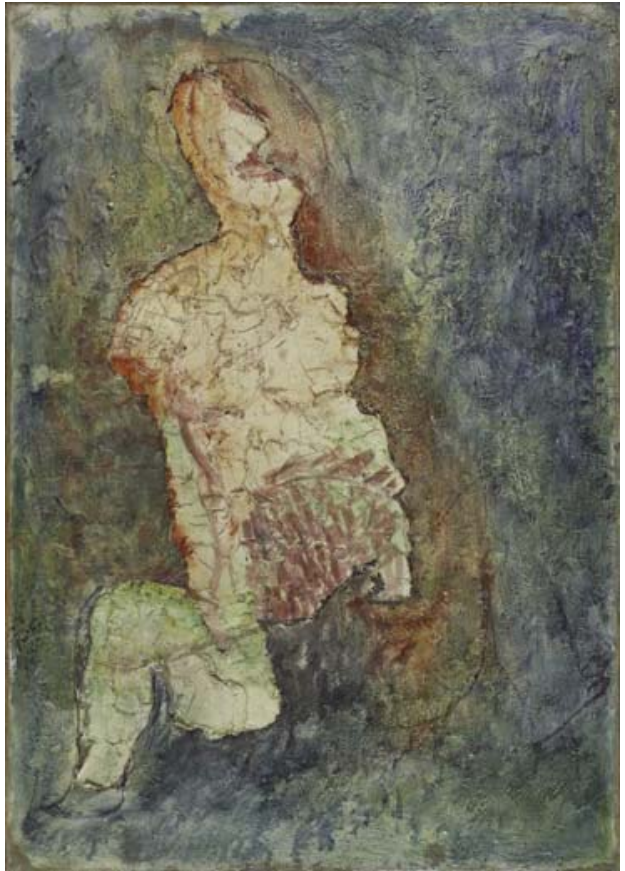

minería, con el propósito de cualificarlos mediante obras de grandes dimensiones y carácter permanente: los earth works. Por otra parte, cómo no reconocer en el informalismo pictórico la referencia a los residuos industriales y los detritus urbanos (figura 9); y cómo evitar la asociación entre las texturas, colores y formas de los materiales en ciertos ámbitos degradados y las de algunos pintores del expresionismo abstracto (figura 10).

El cine, en el género documental y en algunas de sus tendencias narrativas, también ha sido un mediador destacado en este proceso: las películas del neorrealismo italiano, por ejemplo, tienen como escenario los suburbios o los recintos industriales, aunque en vez de sublimar, subrayan la

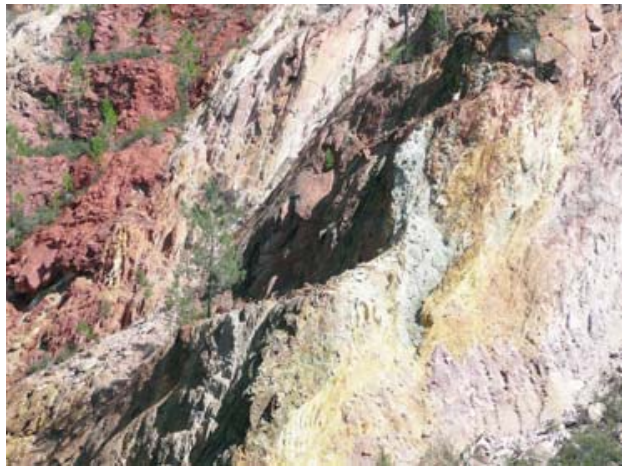

desolación de tales ámbitos, reconocibles por tanto como despaisajes (figura 11). Pero quizás sea la fotografia la que ha hecho una aportación más sostenida: explotaciones mineras, ruinas industriales, lineas de alta tensión que cruzan los campos, emisiones de gases, infraestructuras inacabadas, poblaciones abandonadas son temas recurrentes en ella. Ahora bien cla belleza de la obra redime la fealdad del objeto fotografiado? Parece indudable que la estética del feísmo, con las contribuciones del surrealismo, el informalismo, el art brut y el arte povera entre otros, está en la base de la aceptación de estos temas en los lenguajes artísticos contemporáneos. Pero en todo caso la representación fotográfica y cinematográfica no garantiza su asimilación cultural como paisajes. En los procesos de artelización de paisajes degradados se produce una disociación entre el paisaje-imagen y el paisaje-forma que cuestiona su unidad, puesta de manifiesto en cuanto el primero surge con una intención crítica desde un enfoque social o estético. En tales casos el atractivo de la imagen no se corresponde con la ausencia de cualidades positivas del (des)paisaje real. En este filo se mueven muchas de las obras de Sebastião Salgado:
Figura 11. Fotograma de la película Il deserto rosso de Michelangelo Antonioni, 1964. Fuente: ref. web 6.

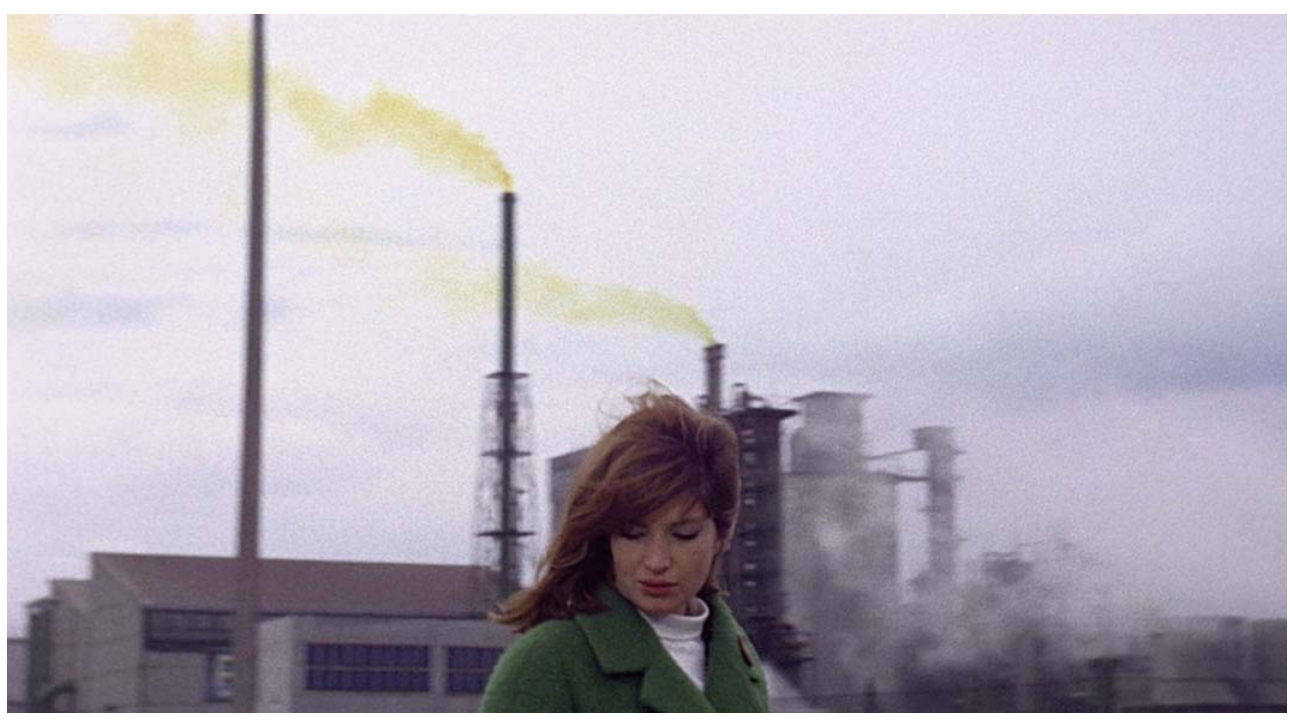


Figura 12. Sebastião Salgado,

Trabajadores en la mina de oro de Serra Pelada (Brasil), 1986. Fuente: Sebastião Salgado, ref. web 7 .

Izquierda. Figura 13. Zinit, región de los Sekzawa, Marruecos, 2015. Fuente: JeanClaude Thiery, ref. web 8.

Derecha. Figura 14. Rembrandt, El buey desollado, óleo sobre lienzo, 1655, Museo del Louvre. Fuente: ref. web 9.

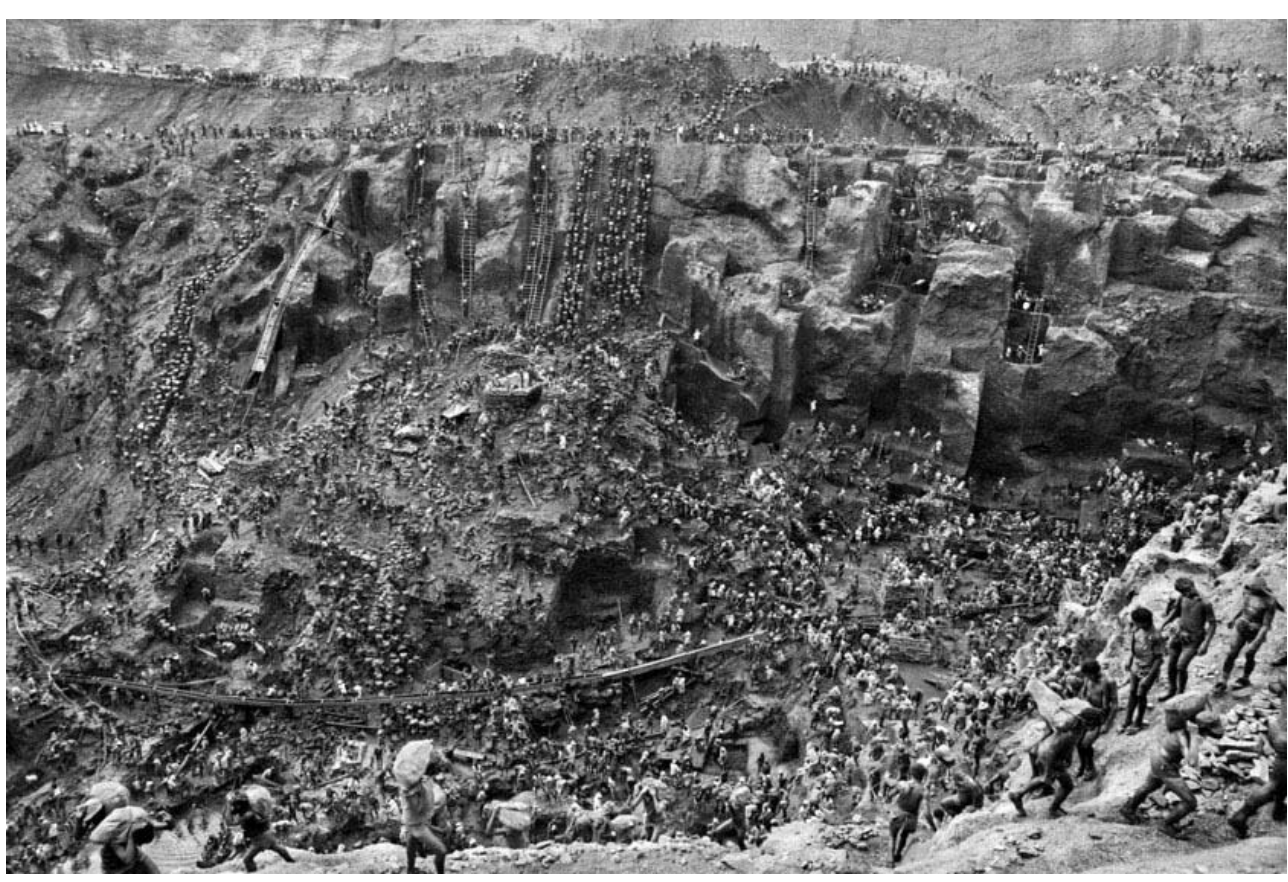

la cuestión es si el autor es capaz, mediante el lenguaje fotográfico, de hacer consciente al espectador de la degradación del ámbito representado, del desgaste del paisaje, en vez de idealizarlo (figura 12).

Aunque evidente, es necesario añadir que la evolución del paisaje-forma por la acción antrópica va ligada a criterios de utilidad y posibilidad. Durante siglos, la lentitud del proceso formativo vinculado al lugar se ha debido, en buena medida, a la carencia de instrumentos o técnicas que permitieran intervenciones más audaces. Sin embargo, en épocas recientes, la revolución industrial primero y la tecnológica después, favorecieron una aceleración caótica de las transformaciones. Así, mientras la configuración de los más bellos paisajes guiados por un modo de actuar inconscientemente adaptativo -el 'pensamiento paisajero' de Berque (2009)- permitia que territo- rio, cultura y mirada mutaran lentamente en paralelo (figura 13), en los dos últimos siglos no sólo hemos destruido muchos de los paisajes generados por nuestros ancestros, sino que hemos llegado a tener graves dificultades para asimilar los producidos por nosotros mismos. Esta dificultad de apropiación se debe, por un lado, a la pérdida de criterios estéticos y de adaptación al lugar, y por otro -tal vez más importante- a la significación de dichas formas: al malestar por lo que representan y transmiten, que no es otra cosa que lo que somos como sociedades, el estado presente de nuestra cultura y nuestro legado futuro.

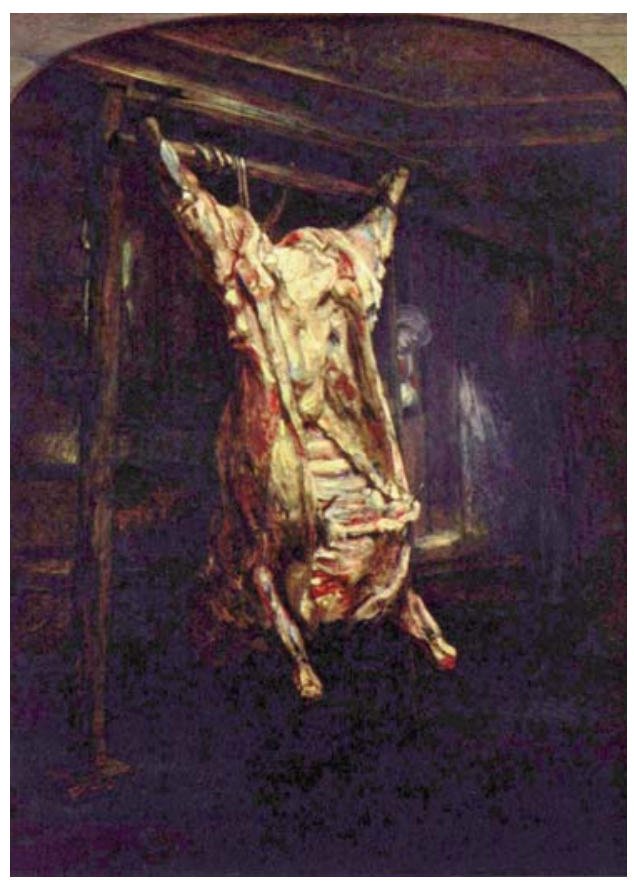



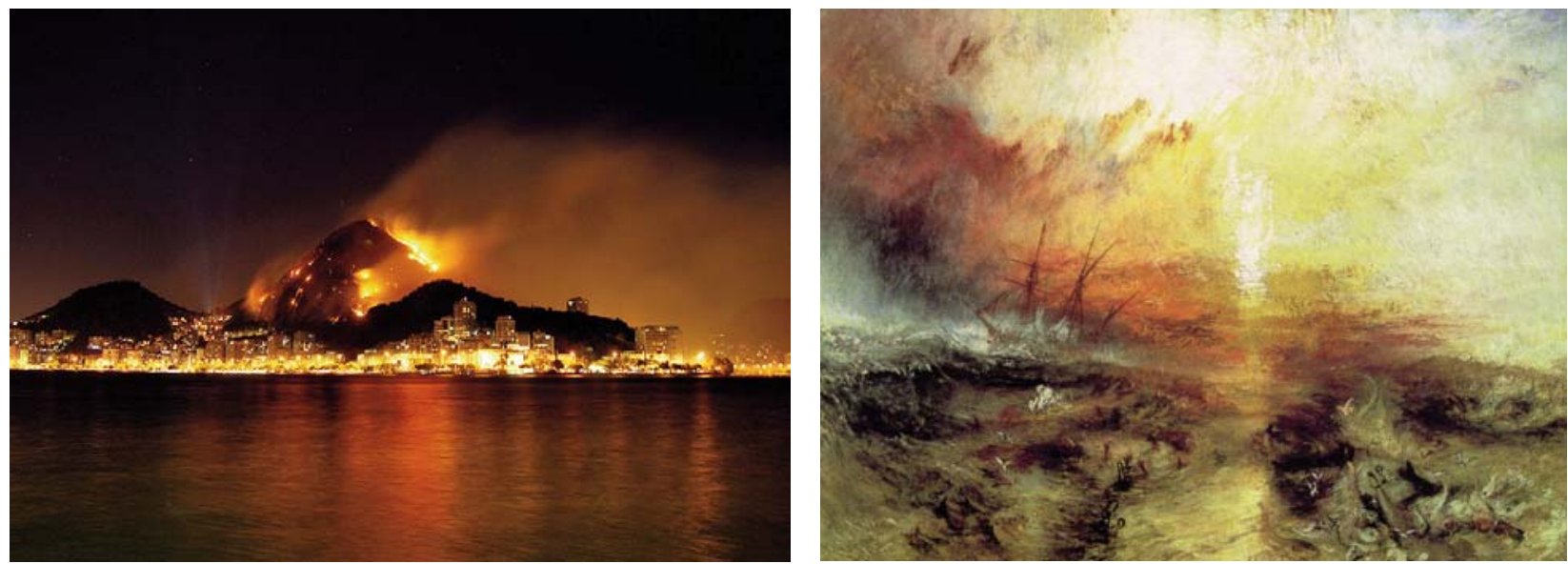

Izquierda. Figura 15. Incendio en Rio de Janeiro, 2010. Fuente: Gustavo Martini, ref. web. 10

Derecha. Figura 16. J. M. W. Turner, Barco de esclavos, óleo sobre lienzo, 1840. Fuente: ref. web 11.

Izquierda. Figura 17. Ruinas de Riveaulx Abbey. Fuente: Dirk Ingo Franke, ref. web 12.

Derecha. Figura 18. Robert Smithson, imágenes de Un recorrido por los monumentos del Passaic, 1967. Fuente: ref. web 13 .

\section{Lo sublime artificial en las ruinas modernas}

Encontramos aquí la paradoja de que lo que resulta atractivo en la obra artística, se vuelve rechazable en la realidad. Aunque, bien pensado, atracción y rechazo se entremezclan tanto en la contemplación de la obra como en la del sitio representado. Algunos de esos paisajes destruidos nos parecen fascinantes por razones estéticas y detestables por una combinación de razones paisajísticas y morales. Semejante situación ya se producía a propósito del concepto de lo pintoresco. Uvedale Price (1971: 39) rechazaba la idea de que todo lo que agradara en una pintura resultara pintoresco en la realidad: el cuadro 'El buey desollado' de Rembrandt muestra cómo una excelente pintura representa una escena que resultaria más bien desagradable en la realidad (figura 14). Por su parte, lo sublime produce sentimientos ambivalentes de horror y deleite: Burke (1985: 92s., 105) lo explicaba observando que tales sentimientos surgen en el espectador cuando se encuentra a salvo del peligro que correría si se hallara en la escena que contempla, pongamos la de un incendio en la noche o la del mar embravecido (figuras 15 y 16). A una idea revisa- da de lo pintoresco recurrió Robert Smithson (2006) para explicar su interés por las ruinas de la contemporaneidad; pero si bien las ruinas de edificios antiguos, sometidas a la usura del tiempo, cubiertas por la pátina de la intemperie y semiocultas por la maleza -esto es, asimiladas al paisaje y entendidas como motivo de remembranzas históricas- eran para Price (1971: 51s.) el mejor ejemplo de lo pintoresco (figura 17), los 'monumentos' del río Passaic, despojados de la nobleza de aquéllos, inacabados y abandonados, se encontraban patéticamente tirados en medio de ninguna parte (figura 18). Aquellos espacios desolados poseían un extraño atractivo que tenía sentido para Smithson dentro de un sistema circular y entrópico en el que naturaleza y cultura se encontrarian en permanente proceso de cambio (Albelda 2013-14).

La carencia de un ideal estético de la naturaleza basado en la apreciación de sus formas primigenias abre así la puerta a otro tipo de intervenciones en el territorio. Pero lo pintoresco cuadra mal con las vastas planicies y los áridos panoramas del paisaje norteamericano que llamaban la aten-
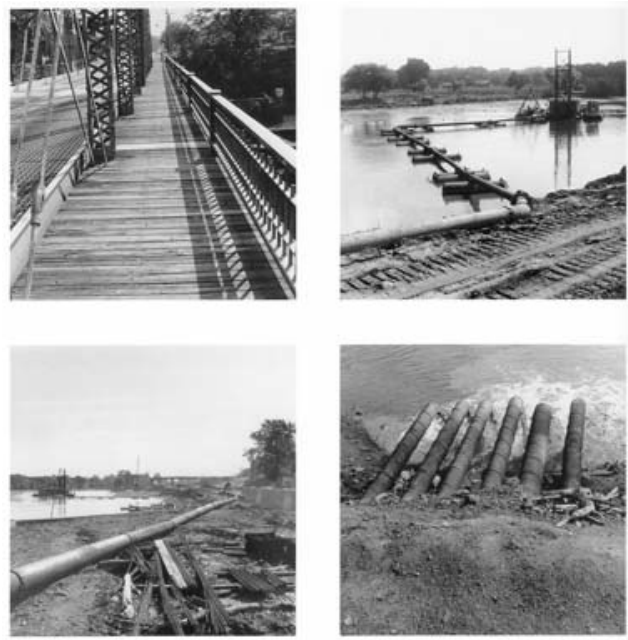


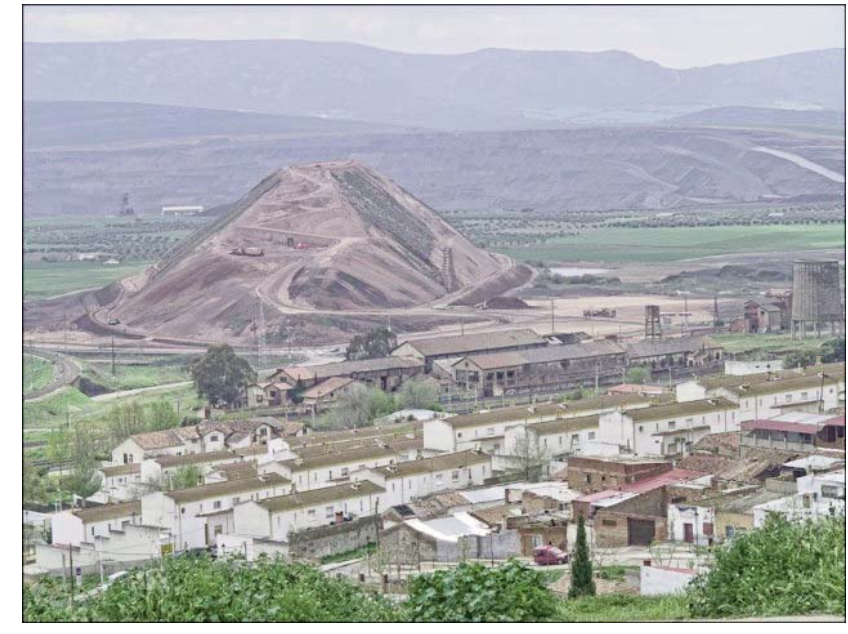

Figura 19.

Escombrera en

Puertollano llamada

'El Terri' (Ciudad

Real). Fuente: autores

ción de Smithson y sus compañeros. En cambio la noción de una sublimidad artificial permite entender su atención a las ruinas del mundo moderno: la producida por los detritus y las huellas -a veces imponentes en su miseria- de las industrias, las megalópolis y las infraestructuras que las sirven (figura 19). Es en el marco de este sublime terrible propio de los paisajes devastados donde adquiere sentido la estética de lo feo, siempre que su grandeza se imponga a la fealdad y que el interés de lo informe y lo deshecho tenga la virtud de compensarla.

Ahora bien, no es legitimo invertir el sentido de estas reflexiones para servir de coartada a la producción de la fealdad allí donde se quiera justificar cualquier actuación que parasite el paisaje en provecho propio, porque el paisaje es un bien común. Berque hace, a este respecto, una constatación descorazonadora: "En las sociedades modernas [...] la práctica habitual engendra fealdad, y por eso nos ocupamos de preservar el paisaje con medidas especiales [...]. El problema es la divergencia entre esta capacidad de apreciar, de decir y de pensar el paisaje, por una parte, y por otra los comportamientos habituales que lo destrozan" (2009: 86ss.). Más adelante, Berque argumenta que la ruptura deliberada con las formas tradicionales, fundamento del arte y la arquitectura modernas, ha tenido por resultado la descomposición del paisaje en campos y ciudades; y rechaza con duras palabras la idea posmoderna de que la belleza se alimenta de contrastes, tensiones y rupturas (2009: 92s.). Su conclusión incita, por tanto, a poner en duda el núcleo mismo de la cultura contemporánea de Occidente.

Es de temer que el diagnóstico de Berque sea, en lo esencial, acertado; lo cual contrasta con el optimismo de Roger (2007: 120 ss.) cuando rechaza la idea de la muer- te del paisaje -achacándola a una mirada desenfocada o perezosa- al observar el descubrimiento contemporáneo de otros nuevos. En cualquier caso, consideramos necesario aprender de nuestros errores para poder mirar al futuro con alguna esperanza que no resulte vana. Para que así fuera deberiamos, en primer término, llegar a la convicción de que no es de recibo aceptar como bueno lo que hay, dando por sentado que el proceso de asimilación cultural cumplirá su papel a través de los lenguajes artísticos. Se trata de iniciar un cambio de raíz que supere los aspectos negativos denunciados por Berque. El argumento de la necesidad económica o social frente a la conservación de un paisaje digno de admiración está viciado, porque en una concepción no antinómica ambas necesidades están culturalmente interrelacionadas: esto, que empieza a aceptarse en el plano medioambiental, debe admitirse igualmente en el plano paisajístico si no queremos sacrificar nuestros paisajes en interés de un progreso mal concebido. El objetivo sería emprender una acción eficaz que abarcara el ciclo de vida completo de las explotaciones industriales, energéticas y mineras. Una acción sostenida por la demanda de los grupos sociales como una cuestión prioritaria de interés cultural; aceptada como una obligación moral por las empresas, sean privadas o públicas; fomentada y regulada por las administraciones en sus distintos niveles, desde el europeo al municipal. Todo ello estaría enmarcado en un cambio de paradigma en nuestra cultura, al que parecen apuntar algunos indicios en los últimos años.

\section{Paisajes de la industria, la energia y la mineria}

Para perseguir este objetivo, una contribución positiva sería identificar y sistematizar procedimientos y criterios que permitan integrar en su entorno los artefactos técnicos de escala paisajística que nuestra sociedad precise; dicho de otro modo, que permitan configurar paisajes nuevos mediante una acción a priori, planificando los aspectos estéticos junto a los técnicos, económicos y medioambientales; o a posteriori, corrigiendo las actuaciones que han consumido o destruido paisajes por falta de planificación. Si bien no haremos juicios de valor sobre los métodos de producción o la necesidad creciente de abastecimiento energético, y dejaremos de lado los problemas de salud pública planteados por las emisiones contaminantes, será preciso hacer algunas consideraciones de indole medioambiental o territorial cuando afecten al modo en que los paisajes degra- 


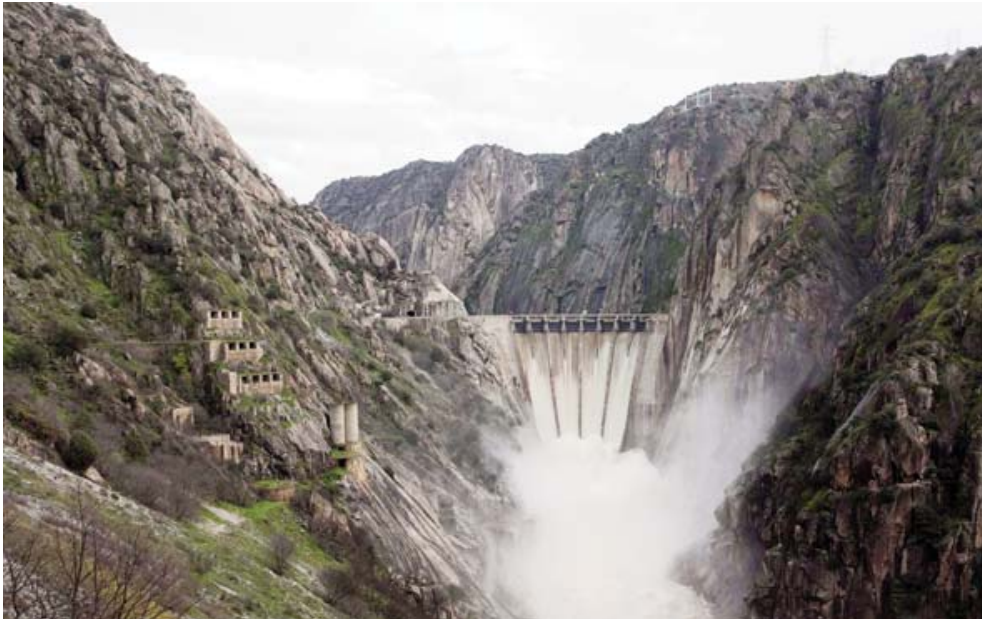

Figura 20. Presa de Aldeadávila

(Salamanca) 1962.

Fuente: ref. web 14.

Figura 21. Corta Atalaya en Riotinto (Huelva). Fuente: Ricardo Martín Herrero. dados son percibidos o comprendidos por la población. Podemos identificar al menos cinco clases de ellos -que en ocasiones se entrecruzan- con distintas circunstancias de apreciación y mecanismos diferenciados de actuación.

\section{Paisajes de sustitución}

Cuando el paisaje original desaparece, produciendo una pérdida absoluta de las referencias vitales de sus habitantes, y es sustituido por otro donde el artefacto técnico adquiere un papel predominante como ocurre en las centrales hidroeléctricas- o la actuación resulta traumática como en las cortas o minas a cielo abiertoestamos ante paisajes de sustitución. En ambos casos los procesos son irreversibles, generándose en un lapso relativamente corto nuevos paisajes sin relación aparente con el original. Estas operaciones son, indudablemente, las que resultan más desconcertantes para los habitantes porque trastocan la forma del lugar y anulan su memoria.

Antes de dar comienzo a la construcción de la presa o a la excavación de la mina,

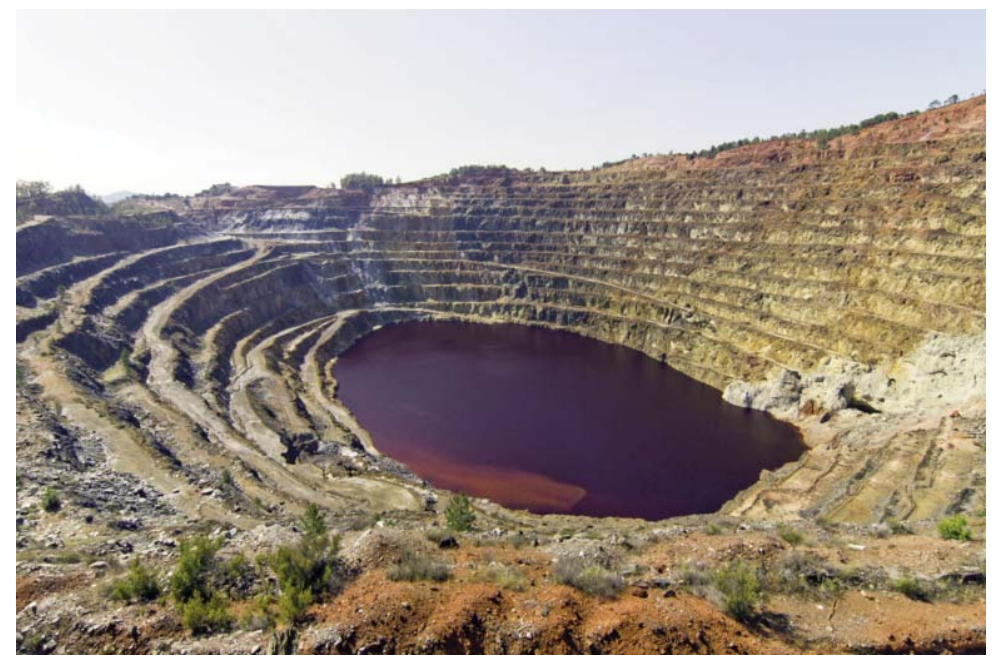

quedan desiertas las poblaciones que serán cubiertas por las aguas o demolidas por la desaparición del suelo en que se asientan. La marcha de los habitantes va seguida de la desaparición de sus casas, de la plaza y la iglesia donde se reunian, del cementerio donde recordaban a los difuntos y de los campos de labor que cultivaban. Con el cambio de fisonomía, en unas pocas generaciones el antiguo paisaje -su conformación, su historia, su patrimonio cultural-, caerá en el olvido, mientras en el nuevo permanecerá un cierto halo fantasmagórico, veladamente alusivo a aquello que falta. Aunque este proceso de sustitución ha de ser entendido como parte de la permanente evolución de los paisajes, para que la memoria perdure es necesario que la transformación del paisaje-forma vaya acompañada de un cuidadoso proceso de reconfiguración del paisajeimagen.

Para ello habrá que dotarlo de un equilibrio que permita la convivencia de los requisitos de uso derivados de la transformación con los valores patrimoniales, estéticos y medioambientales preexistentes. En este sentido, la elección del emplazamiento de una presa y el manejo del contraste (y de las conexiones) entre ella y su entorno son factores clave en su futura adaptación: véase el caso de la de Aldeadávila (figuras 20), en el río Duero, que con su curvatura, nervios y enlaces parece expresar al mismo tiempo las condiciones del sitio y la potencia de la pieza construida que se opone a la presión del agua. Pero no hay consideraciones equivalentes en el caso de la mina: el impresionante agujero circular de la corta Atalaya en Riotinto (figura 21) sólo es entendible como un violentísimo corte en el terreno. Ahora bien, la apreciación de lo nuevo no ocurre del mismo modo para los foráneos que para los habitantes locales; serán éstos, herederos de quienes dieron al paisaje su forma y depositarios de las tradiciones ligadas a él, los más capacitados para conservar su memoria -lo cual no impide a un observador atento advertirla igualmente-; en cambio, serán los foráneos quienes puedan apreciar las cualidades del nuevo paisaje de modo más objetivo: para éstos el agua del pantano, por ejemplo, constituirá un valor añadido, cosa que no ocurrirá para los naturales durante varias generaciones. Si bien estos aspectos están interconectados y no es posible desvincularlos del llenado del embalse o del vaciamiento de la mina, será necesario realizar actuaciones integrales capaces de generar nuevos valores positivos con los que se pueda establecer una relación de empatía. 

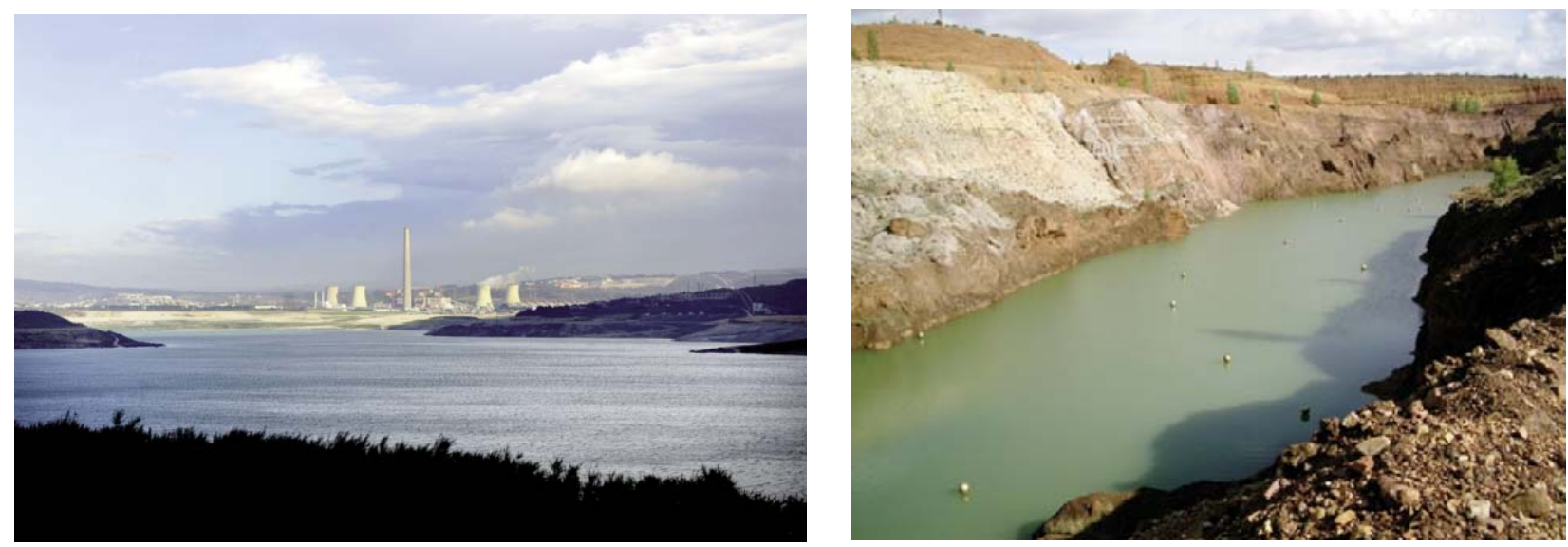

Izquierda. Figura 22. Lago de As Pontes con central térmica al fondo, La Coruña, 2012. Fuente: Endesa, ref. web 15.

Derecha. Figura 23. Josep Ginestar, Te busqué hasta en lo más profundo, Instalación de 27 esferas doradas en la mina Ojos Negros (Teruel) 2005. Fuente: Diego Arribas.

Figura 24. Descubierta de Garzweiler (Alemania). Fuente: ref. web 16.
Tales actuaciones deberian producirse en varias direcciones: habría que contemplar, por un lado, los aspectos medioambientales, de grave impacto en estos casos, que se pueden minimizar en los embalses con el tratamiento de las riberas y en las minas con la canalización de las redes fluviales que impidan la contaminación del agua, así como la descontaminación de suelos y la regeneración de los ecosistemas en las escombreras. Por otro, los relacionados con el día a día de los lugareños: su reubicación en nuevos asentamientos en la propia región, el uso en las nuevas edificaciones de materiales y formas que no rompan con la tradición constructiva, su recolocación laboral dentro de la zona, el traslado de los restos de sus difuntos a las cercanias, etc. Por último, la creación de hitos significativos de la mano del arte, la arquitectura o el paisajismo a través de los cuales quepa establecer vínculos simbólicos con el nuevo paisaje al tiempo que se mantiene la memoria del lugar. En las minas de As Pontes (La Coruña) y Ojos Negros (Teruel) se han seguido distintas vias para lograrlo: en la primera se ha formado un lago mediante el llenado de la corta, generando un paisaje bucólico pero engañoso, porque borra el testimonio de lo ocurrido en el sitio (figura 22); en la segunda se ha conservado el registro geomorfológico de la explotación con objeto de no olvidar el pasado, llamando la atención sobre él mediante intervenciones artísticas a propósito (figura 23).

\section{Paisajes de recuperación}

Cuando la índole transitoria de la actuación permite restituir en cierta medida el estado original se producen los paisajes de recuperación. Ocurre en explotaciones al descubierto de desarrollo horizontal, como los yacimientos carboníferos en que la explotación de la veta progresa no por profundización del cono excavado, sino por avance del frente en la dirección de aqué1la. A veces ocupan grandes extensiones, como la descubierta de lignito de Garzweiler, en Alemania, que a lo largo de su vida útil, prevista hasta 2045, llegará a ocupar los terrenos de una docena de pueblos (figura 24); o la mina Emma en Puertollano, cuya veta tiene doce kilómetros de longitud por dos de anchura y un periodo previsto de explotación de unos treinta años (figura 25). Cuando esta forma de explotación se realiza mediante la llamada 'mineria de transferencia', es decir, utilizando los materiales extraídos para recuperar el terreno sin necesidad de acumularlos en escombreras definitivas, el impacto negativo disminuye considerablemente. De este modo es posible rehacer la topografia, aunque con una cierta elevación resultado del esponjamiento de las tierras excavadas, que se irán asentando con el tiempo (figura 26). Ahora bien, no se trata de volver forzosamente al estado original ocultando la operación realizada, sino de recrear un paisaje no mimético pero congruente con su entorno.

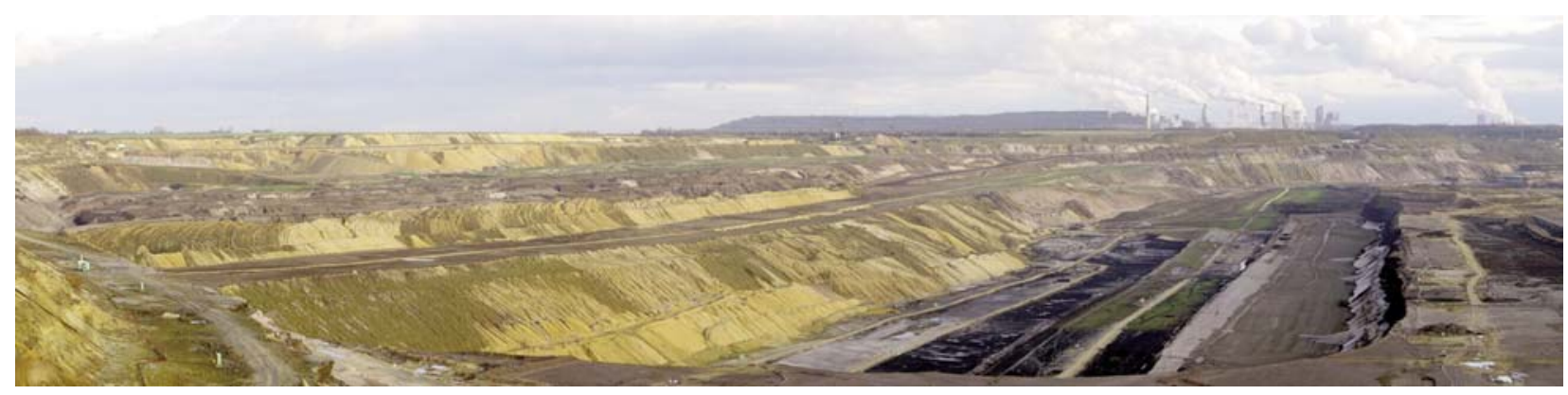



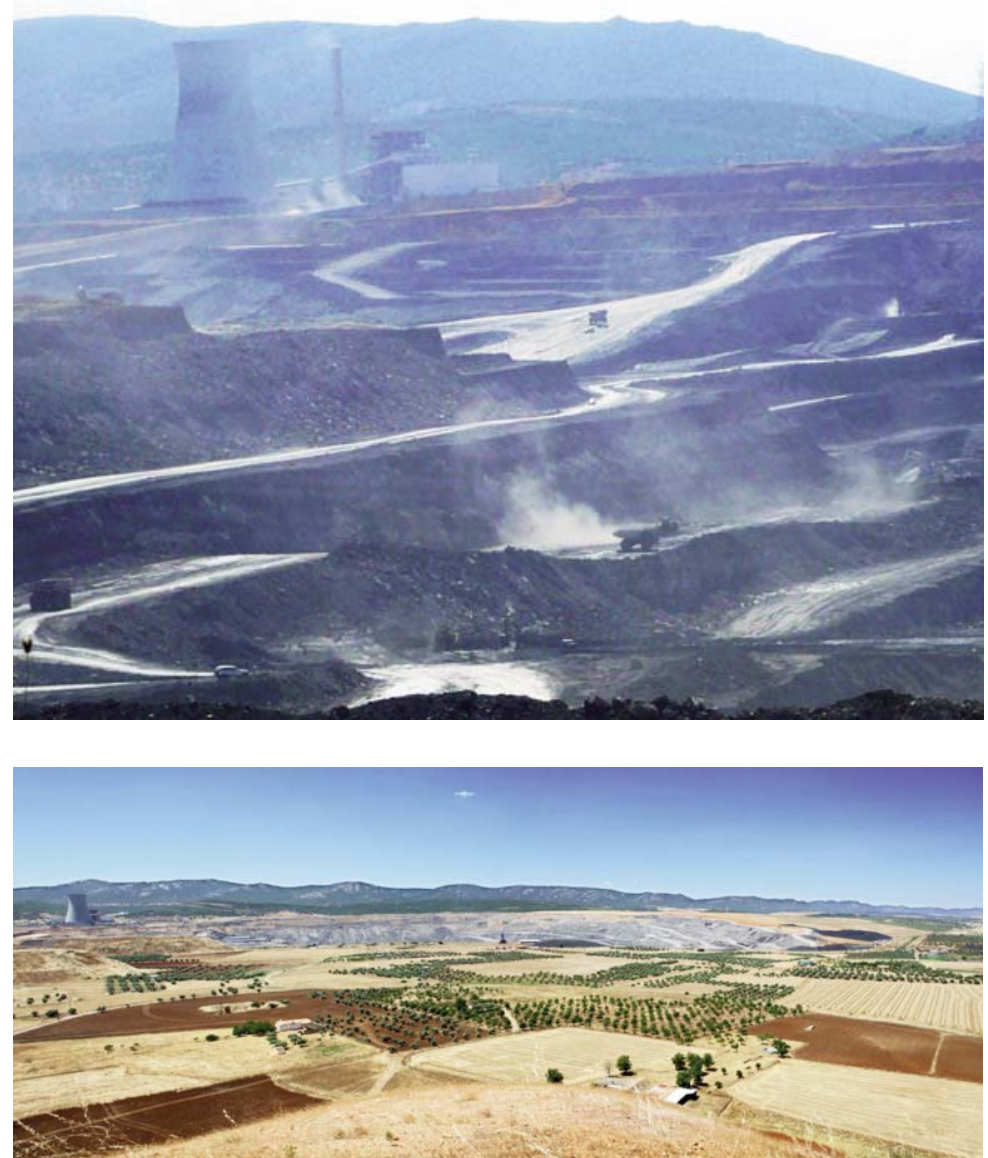

Figura 26. Terrenos restaurados de la mina Emma en Puertollano (Ciudad Real). Fuente: ref. web 17.

\section{Figura 25. Mina} Emma en Puertollano (Ciudad Real). Fuente: autores.

Figura 27. Central térmica de La Robla (León). Fuente: ref. web 18.

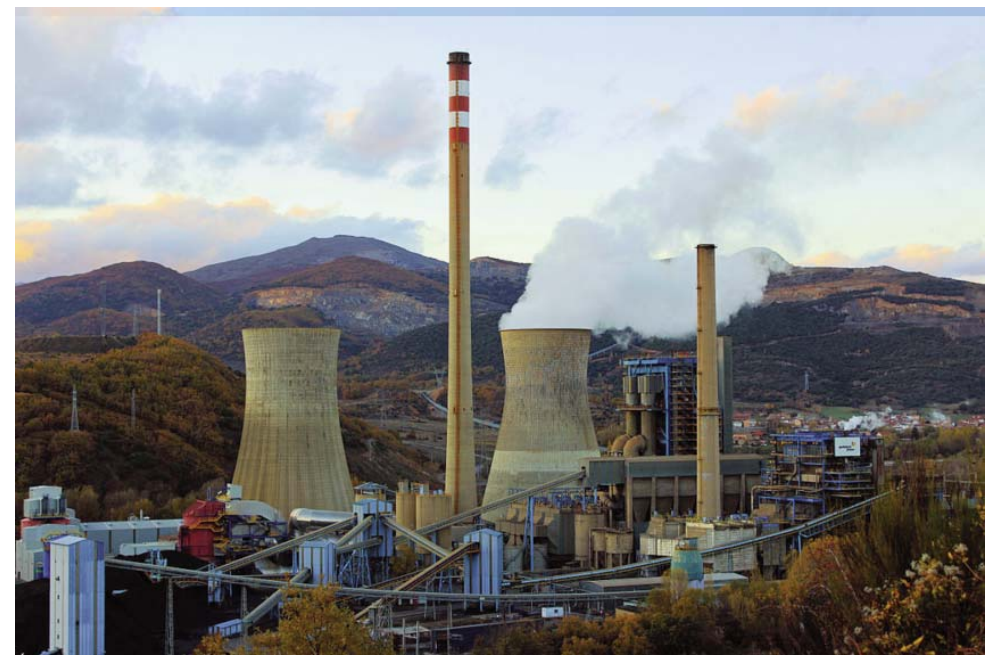

excavación, habrá que mejorar las tierras superficiales y los estériles de la extracción mediante procesos de descontaminación de suelo, ${ }^{4}$ restituir las redes fluviales evitando la contaminación de aguas y regenerar la cubierta vegetal en condiciones análogas a la situación previa, para favorecer la estabilización de nuevos procesos ecológicos. Cuanto menor sea el tiempo invertido entre la retirada inicial de la cubierta vegetal y la restauración paisajística, menor será también su repercusión social; pero de darse, habria que seguir criterios semejantes a los planteados para los paisajes de sustitución.

Ahora bien, esta reinterpretación no pretende eliminar el rastro de la extracción minera sino conferir al paisaje unas condiciones de calidad. Dado que la mina pasa a formar parte de la memoria del lugar, una vez finalizada su vida útil su huella debe quedar en el paisaje: el mantenimiento de algunas de las instalaciones destinándolas a un nuevo uso, de maquinaria o incluso de algún rasgo del terreno afectado a modo de signo recordatorio, contribuiría a este objeto. El asunto de las centrales térmicas asociadas a la mina, constituye un problema añadido al que nos referiremos en el apartado siguiente.

\section{Paisajes de protección}

A diferencia de las dos clases de paisaje anteriores, en los siguientes no desaparecen los rasgos formales del emplazamiento, pero se modifica su entorno al levantar artefactos de fuerte presencia que se imponen en el panorama. Así, llamaremos paisajes de protección a aquéllos en que la aparición de instalaciones y artefactos técnicos de gran altura o volumen adquiere un papel preponderante -generalmente asociado a emisiones atmosféricas que atestiguan los problemas de contaminación vinculados a ellos-, afectándolos de tal modo que se hace necesario tomar medidas protectoras. Nos referimos principalmente a las centrales térmicas y nucleares. En las primeras, las altas chimeneas y las emisiones de gases y subproductos resultantes de los combustibles fósiles empleados constituyen la imagen característica (figura 27). En las centrales nucleares son las cúpulas que albergan el reactor y sobre todo las torres de ventilación las que cumplen ese papel, pero el humo expulsado por éstas es vapor de agua; sin embargo su presencia recuerda el peligro potencial que un fallo en el sistema puede provocar (figura 28). En ambos casos, los humos resultan inseparable de su imagen. 


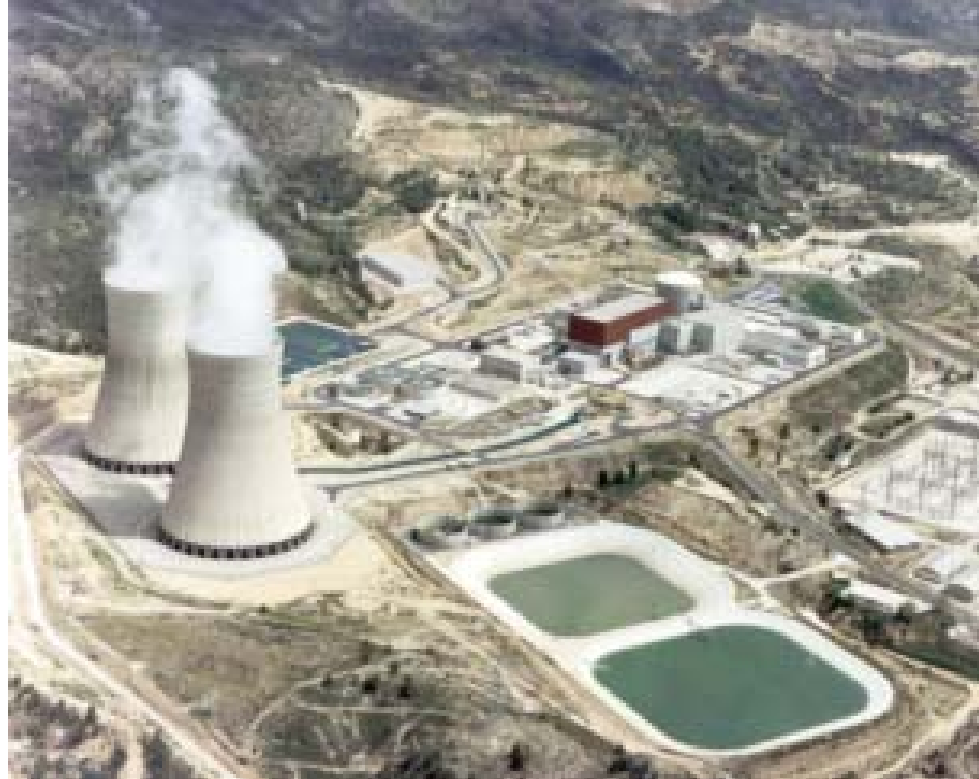

Figura 28. Torres de refrigeración de la central nuclear de Cofrentes, Valencia. Fuente: ref. web 20.

Figuras 29 y 30. Geofrey Jellicoe, Blue Circle Hope, 1943-93: vista y planta (Michel Spens: 1994).
Pues bien, mientras se desarrollan e implantan energias menos contaminantes, es posible tomar medidas de salvaguarda visual del entorno que las acoge: ambas clases de centrales cuentan al menos con la ventaja de no ocupar grandes extensiones. No se trata de ocultar los humos tarea por otra parte imposible- ni los volúmenes relevantes: torres, cúpulas o chimeneas pueden tener un valor plástico y anuncian desde lejos su existencia; pero si de atenuar el impacto paisajístico del conjunto mediante el enmascaramiento de las construcciones bajas que suelen ser las que presentan mayor desorden visual. Esto se logra mediante barreras que pueden combinar movimientos de tierra para formar colinas bajas con masas arboladas, cuyas dimensiones y posición se determinan mediante el estudio de las cuencas visuales. De este modo se constituye un paisaje transformado, que asume los elementos elevados como hitos visibles pero encubre desde ciertos puntos de vista los bajos confusamente colocados. En las cen- trales térmicas asociadas a explotaciones mineras, tales previsiones deben ser incluidas en el conjunto de actuaciones globales antes planteadas.

Medidas semejantes de protección visual son también aconsejables en otras instalaciones con fuertes efectos de degradación sobre en el paisaje, como las refinerias de petróleo y las fábricas de cemento. Éstas últimas presentan una combinación de varios de los problemas antedichos: las instalaciones trastornan la imagen del paisaje por sí mismas; además modifican el relieve del terreno al estar cerca de canteras de caliza, cuya explotación produce cortes verticales en él, y al almacenar los residuos en escombreras; en tercer lugar, provocan emisiones de partículas y polvos resultantes del proceso de manejo y transporte de materiales, que son peligrosos para la salud: por esta razón es habitual su alejamiento de las poblaciones. Ahora bien, se puede cuando menos planificar la evolución de la cantera, de las escombreras y de las propias instalaciones en periodos largos. Y cuando la calidad del paisaje lo exige, proteger las vistas utilizando las escombreras y mediante pantallas vegetales que irian cambiando en función de esa evolución, así como compatibilizar la explotación con los trabajos de recuperación del paisaje planteados en casos anteriores. La planificación paisajística de la fábrica de Blue Circle Hope, en el parque nacional de Peak District, Gran Bretaña, realizada por Geoffrey Jellicoe (Spens 1994: 60s.) y mantenida entre 1943 y 1993, sigue siendo ejemplar a este respecto (figuras 29 y 30).

\section{Paisajes potenciales}

Entendemos por paisajes potenciales los formados por aquellas instalaciones en que cabría sacar partido de sus cualidades formales si se dispusieran de acuerdo con
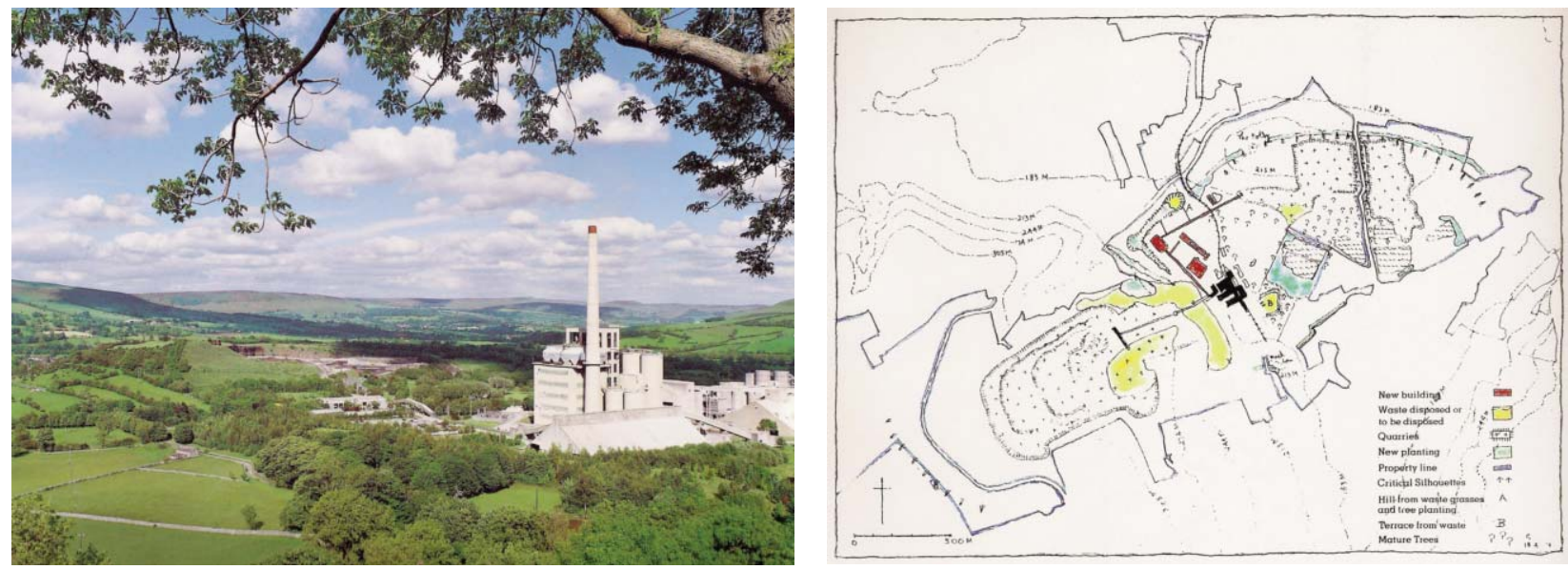
Figura 31. Luigi Cosenza y Pietro Porcinai, sede de Olivetti en Pozzuoli (Italia), 1950-1979: planta. Fuente: ref. web 20.

Arriba. Figura 32. Huerto solar en Amareleja, Moura (Portugal). Fuente: ref. web 21.

Abajo. Figura 33. Central termosolar de Sanlúcar la Mayor (Sevilla). Fuente: Mario Sánchez, ref. web 22.

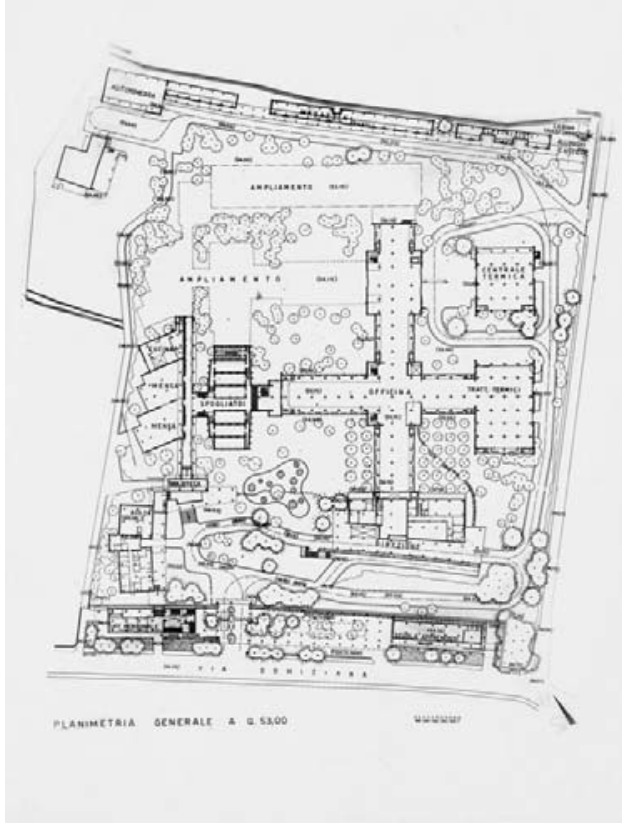

la morfología de su entorno. Es, desde luego, el caso de los complejos fabriles, que pueden proyectarse teniendo en cuenta su integración en el paisaje, como ocurre con la sede de Olivetti en Pozzuoli, Italia, de Luigi Cosenza y Pietro Porcinai (figura 31), o con la fábrica Angli en Herning, Dinamarca, tras la intervención de Carl Th. Sorensen. Es también el caso, cada vez más presente, de las energías renovables que, justificadas por su indiscutible papel de alternativa no contaminante a las energías convencionales, ocu-
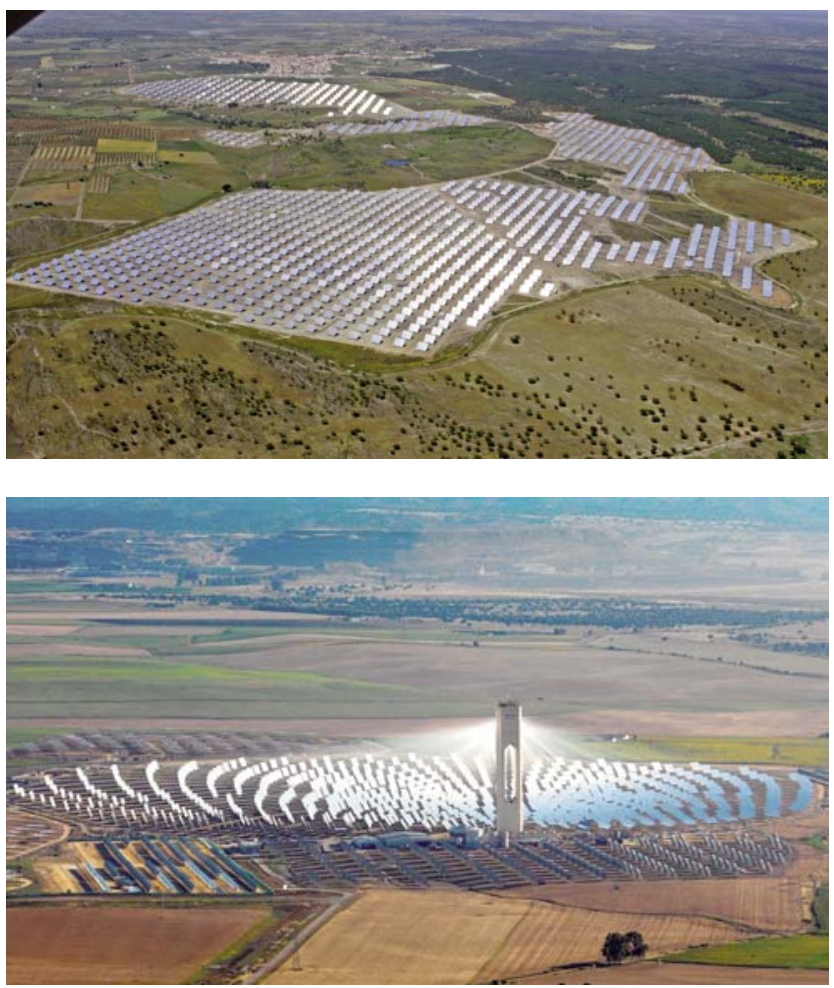

pan grandes extensiones de terreno con artefactos de distinta factura sin tomar en consideración criterios básicos de integración en el entorno. Se entiende que, al estar sus elementos montados sobre el terreno, al final de su vida útil podría procederse a su desmontaje dejando, al menos en teoria, una huella casi nula, lo que convertiría los posibles desmanes en potencialmente reversibles. Estas dos ideas -energías limpias e instalaciones reversibles- marcan la diferencia con los casos anteriores. Sin embargo, no parece que debamos considerarlas instalaciones temporales en el corto plazo: en la hipótesis de sustitución progresiva de las energías contaminantes, habrá que contar con su permanencia a plazo largo, aunque algunas localizaciones puedan cambiar con el tiempo. Por tanto estamos obligados a considerar su incidencia en el paisaje.

En primer lugar, en cuanto a la forma de sus elementos es necesario hacer alguna distinción. Las placas solares poseen figura, color y textura distintos a casi cualquier componente natural del paisaje, por lo que resultan ajenas a los entornos que habitualmente ocupan: las centrales fotovoltaicas o huertos solares podrían describirse como una disposición regular de rectángulos grises levantados y girados respecto al terreno. Hay en ellos unos efectos de distorsión del relieve, mosaico de color y fragmentación de la superficie (figura 32): quizá la disposición de las placas en bandas adaptadas a la topografia siguiendo las curvas de nivel permitiera expresar plásticamente la morfología del terreno en que se apoyan. A su vez, en las centrales termosolares, la concentración de las superficies reflectantes en torno a la torre y los reflejos dirigidos a ésta formalizan un objeto extraño, aunque de notable potencia plástica, que aparece a nuestra vista con la fascinación propia de un escenario de película de ciencia ficción (figura 33). No cabe ninguna corrección que tienda a matizar su presencia en el paisaje, como no fuera la ocultación parcial con barreras visuales bajas enunciada para los paisajes de protección.

En cambio, en el caso de los parques eólicos las formas estilizadas y aerodinámicas de los aerogeneradores y su dispersión en el territorio producen un efecto menos chocante, quizás, que los anteriores; pero su enorme tamaño, el frecuente desorden de su distribución y el ruido que producen en las inmediaciones dificultan considerablemente su encaje en el paisaje (figura 34). Por tanto, dados el tamaño de los elementos y los requerimientos técnicos de su localización, es imprescindible hacer una 

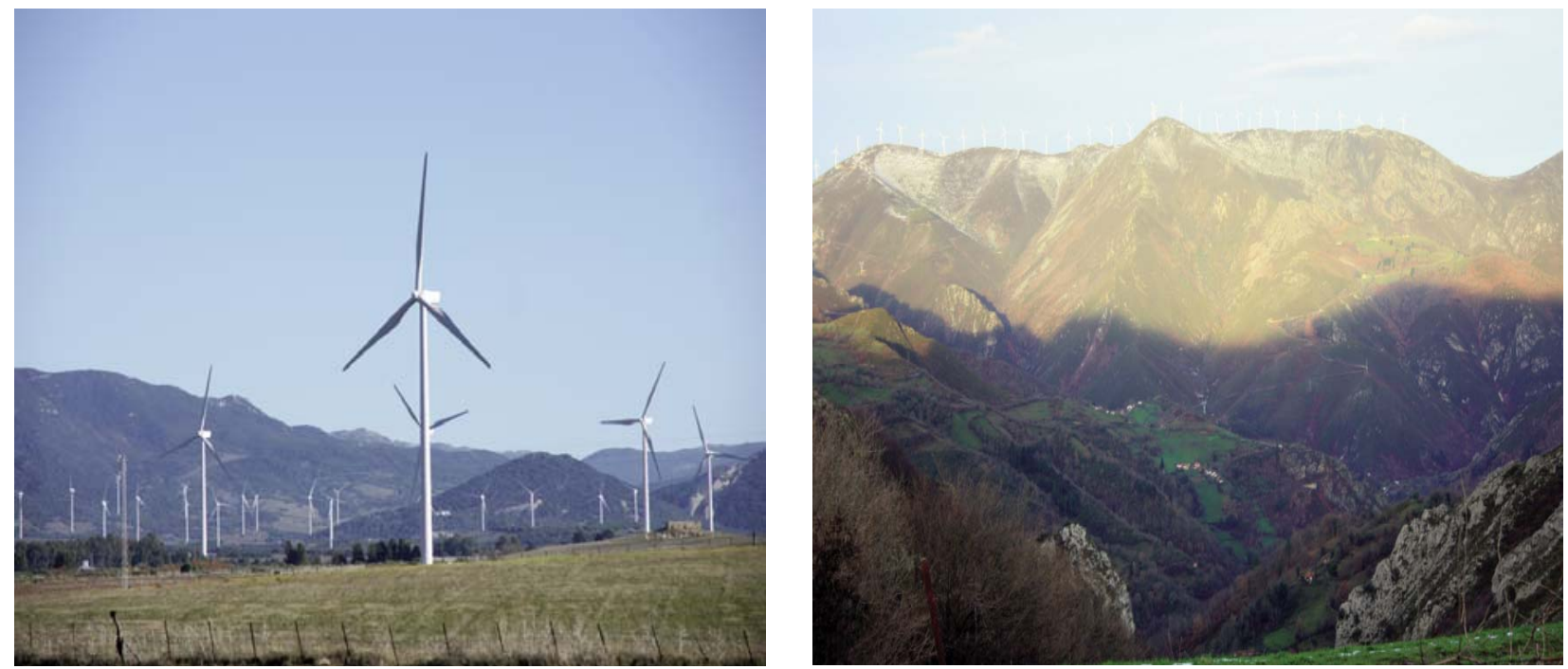

Izquierda. Figura 34 Parque eólico de Facinas (Cádiz). Fuente: autores.

Derecha. Figura 35. Parque eólico en sierra de Begeda, Cordillera Cantábrica, Asturias. Fuente: ref. web 23.

Figura 36. Torre del tendido eléctrico en las cercanías del Parque Nacional de Ordesa y Monte Perdido (Huesca). Fuente: Autores.

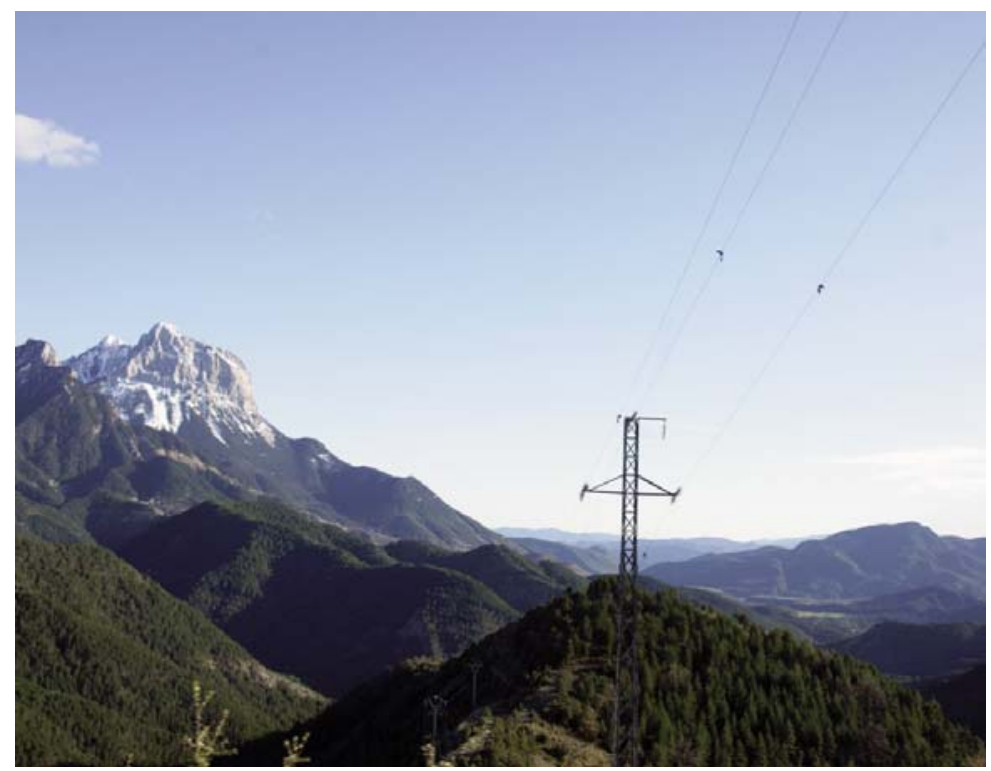
aspas de los aerogeneradores. En el plano paisajístico, se trata de prevenir la contaminación visual de paisajes dignos de conservación por su propia calidad estética o por constituir el entorno visible de poblaciones históricas, edificios monumentales o yacimientos arqueológicos de valor apreciable. Para ello los aerogeneradores deben evitar la ocupación de sus cuencas visuales, especialmente las posiciones en las lineas de cornisa, que son más favorables para los vientos pero también las más visi- bles (figura 35). Dicho lo cual, la ordenación de los parques eólicos, especialmente en terrenos abiertos, debería tener en cuenta los modos geométricos de agrupación en alineaciones, bandas o retículas a distancias constantes, con el fin de lograr nuevos valores paisajísticos, ligados a algunas formas de land art, que permitan su asimilación cultural; o bien considerar su instalación en zonas escogidas de mar abierto.

Un caso particular es el de las redes de distribución de energía eléctrica, que atraviesan el territorio habitado en todas direcciones. En nuestras ciudades se ha generalizado el uso de conductos subterráneos, pero su coste es una seria dificultad para implementarlos fuera de ellas; así que los tendidos eléctricos se han vuelto familiares en pueblos y campos. Pero este hecho no evita que su presencia constante cualifique negativamente el paisaje, especialmente en los lugares de mayor calidad paisajística (figura 36 ). En ellos sería necesario tomar en consideración los puntos de vista panorámicos para alejar los tendidos de su proximidad; en ocasiones es posible, además, un cierto camuflaje llevándolos por detrás de bosques y arboledas; y siempre es factible examinar las cuencas visuales para evitar los tendidos más disruptivos. Esto adquiere particular importancia en las estaciones de transformación y distribución, a las que entran y de las que salen multitud de tendidos que producen una confusión visual extraordinaria: debería procurarse ubicarlas en sitios discretos. Una posibilidad recientemente planteada es rediseñar las estructuras ligeras de las torres que soportan los conductores para obtener apoyos escultóricos o humanoides de forma variable, que pueden resultar interesantes en algunos emplaza- 


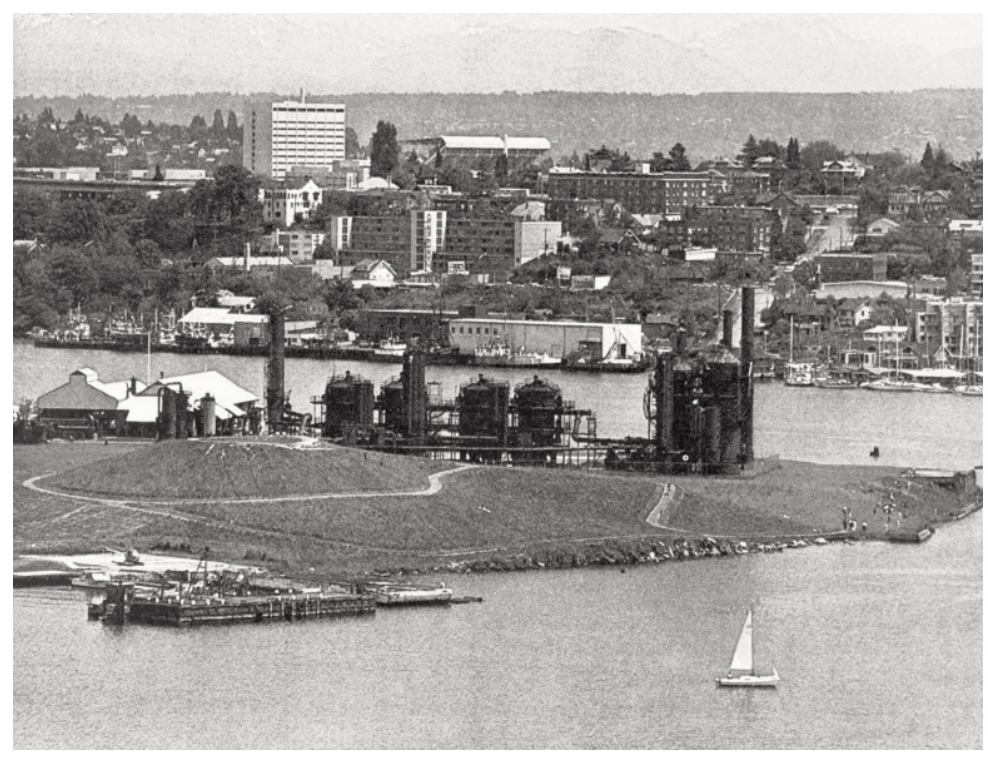

Figura 37. Richard Haag, Gas Work Park, Seattle, 1972. Fuente: Sutherland Lyall. 1991. Landscape: Diseño del espacio público. Barcelona: Gustavo Gili.

Figura 38. Peter Latz, parque Duisburg Nord (Alemania), 1990-

2002. Planta. Fuente: Peter Latz \& Partner ref. web 24. mientos, aunque no resuelven el problema de fondo. 6

Por último, los paisajes de agregación son aquéllos en los que, al acabar el periodo productivo, tiene lugar la transformación de las instalaciones en una nueva clase de espacio público. Se parte de los edificios, maquinaria e infraestructuras que funcionaron en las minas subterráneas, los altos hornos, los depósitos de gas, las centrales térmicas o las estaciones ferroviarias durante sus años de su actividad. Los nue-

\section{Paisajes de agregación}

vos usos permiten evitar el abandono y la degradación de las instalaciones, además de los inconvenientes que supondria su desmontaje, y constituyen una buena oportunidad de creación de empleo y reactivación de la economía de la zona, evitando en parte la emigración de los trabajadores de las industrias desaparecidas.

La operación de reutilización no consiste sólo en la rehabilitación de algunos edificios y en la programación de nuevos usos culturales o recreativos, sino en la reordenación del conjunto introduciendo componentes vegetales, arquitectónicos y acuáticos que se superponen a los restos conservados de las instalaciones preexistentes mediante un serie planificada de intervenciones puntuales: apertura de espacios, plantación de arboledas, consolidación de escombreras, reapropiación de canales o estanques, introducción de cultivos ornamentales y utilitarios, reaprovechamiento de componentes mecánicos como juegos infantiles, reconversión de edificios, reutilización de piezas de desecho etc. En cuanto al terreno, suele ser necesario implementar medidas medioambientales como la descontaminación de suelos y de aguas o la introducción de asociaciones vegetales $\mathrm{y}$ especies animales que colaboren en la creación de nuevos ecosistemas. De este modo se propicia una lectura de estos nuevos paisajes por capas que dan visibilidad a los estados anteriores -natural, agrícola y fabril- agregando uno nuevo: la evolución

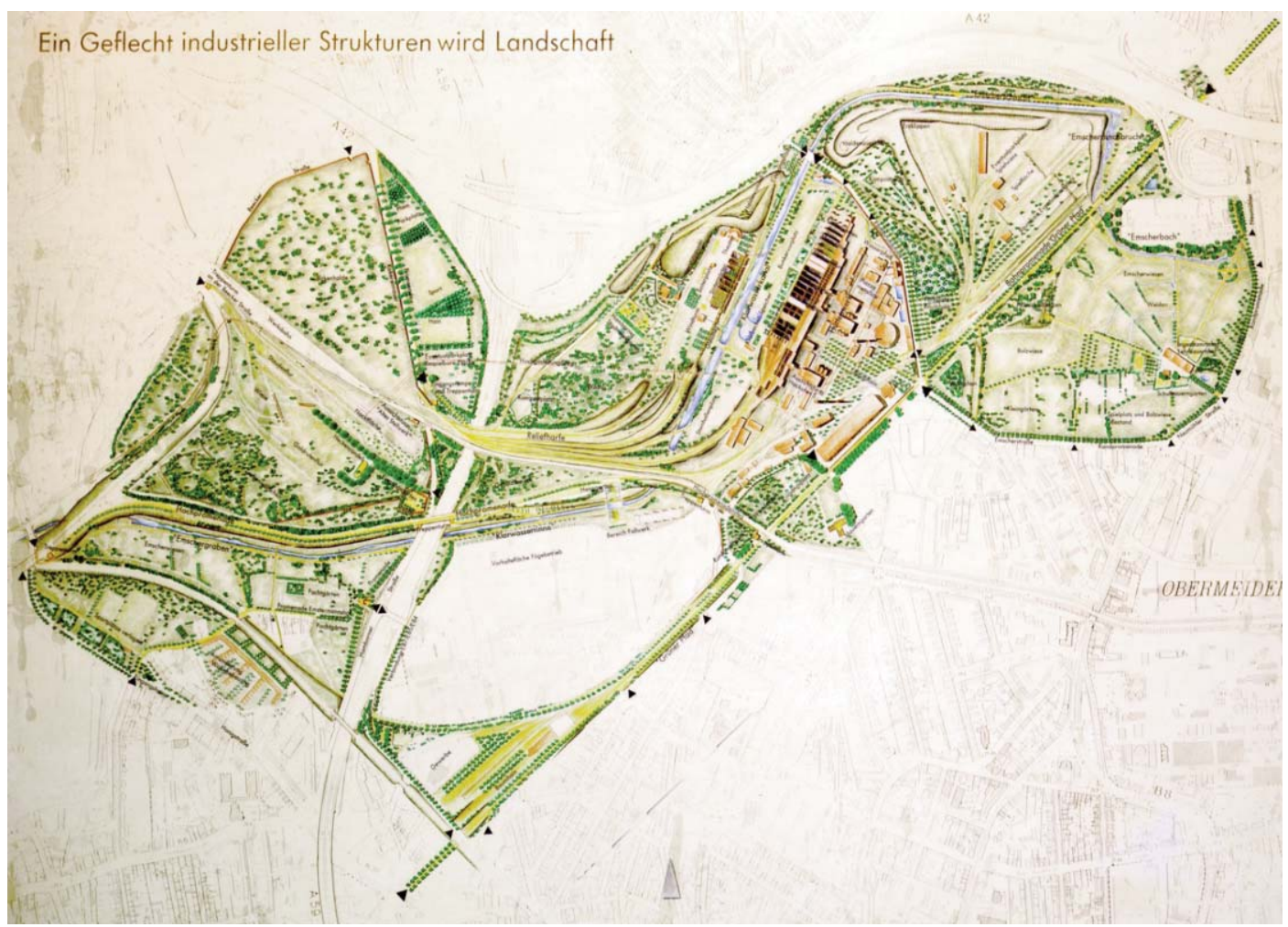




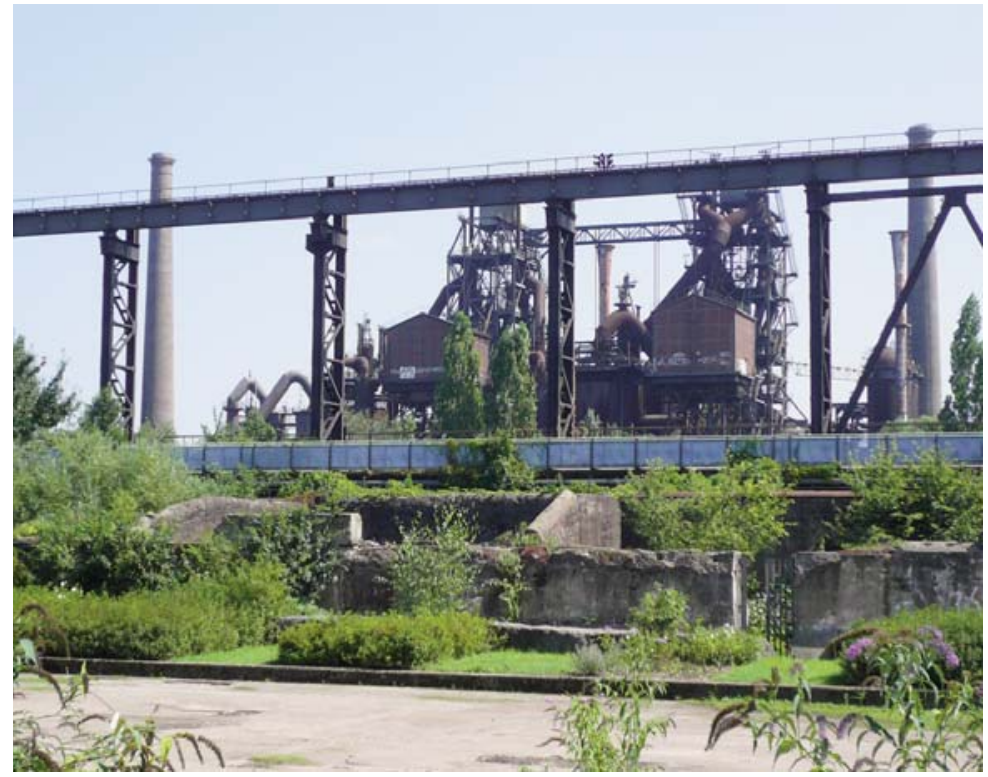

Figura 39. Peter Latz, parque Duisburg Nord (Alemania), 19902002. Fuente: autores

Figura 40. Peter Latz, parque Duisburg Nord (Alemania), 19902002. Fuente: autores. del sitio se pone de manifiesto mediante la vez acoge una multiplicidad de usos, no tanto planeados como sugeridos.

El primer caso reconocido de este tipo de actuaciones es el del Gas Work Park en Seattle de Richard Haag, iniciado en 1972, con la reconversión de una antigua fábrica de gas en parque público (figura 37). Sin embargo fue en el decenio de 1990, tras la crisis de la industria siderometalúrgica en los ochenta, con la reconversión de la cuenca del Rhur en el Parque Emscher que se extiende en una superficie de unos 800 kilómetros cuadrados entre Dortmund y Duisburg- cuando se empezaron a generalizar actuaciones como éstas. Entre el gran número de transformaciones realizadas destacan la del complejo minero de Zollverein, en Essen, y la de las acerias simultaneidad de las referencias, que a su

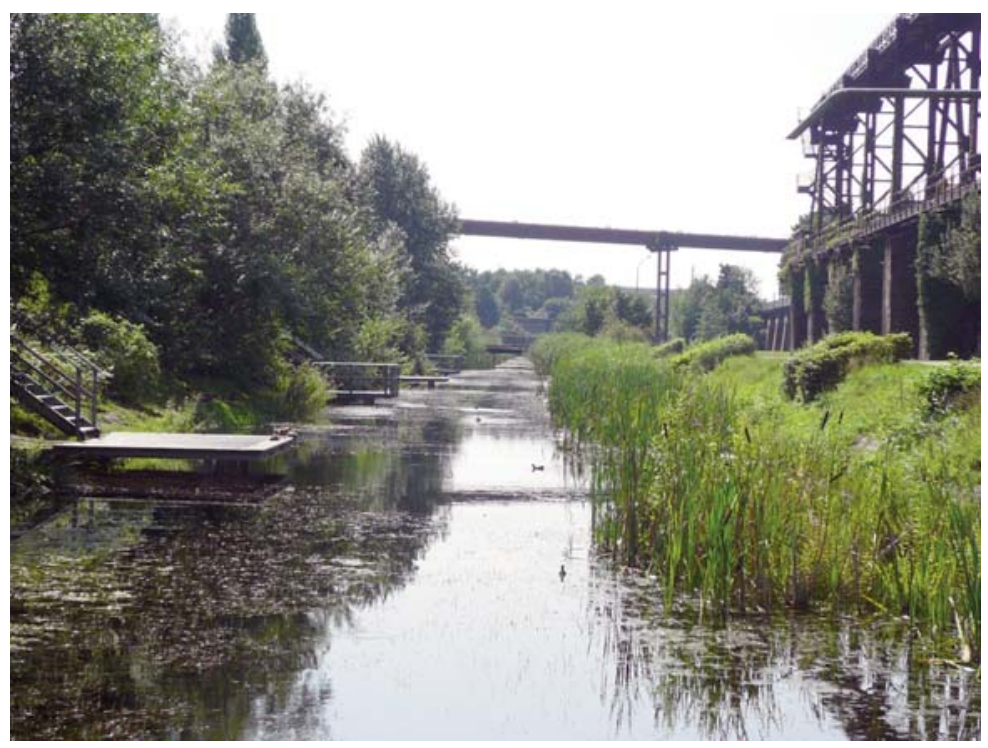

Thyssen en Duisburg Nord. Pero mientras en el primero el propósito era rehabilitar los magníficos edificios con nuevos usos culturales (escuela de danza, museo de diseño, librería) y abrir las instalaciones al visitante, añadiendo como hito un nuevo edificio de SANAA junto a la entrada principal, en Duisburg se puso el énfasis en la recuperación de los espacios intermedios y de las áreas abiertas (figuras 38 y 39). Así, no sólo se puede recorrer un alto horno abandonado, encontrar una escuela de submarinismo en un antiguo depósito de gas o celebrar un ciclo de cine en una nave rehabilitada, sino que donde había un vacío entre las instalaciones hay ahora una arboleda o una plaza, en los depósitos de materiales han aparecido habitaciones de jardin, las conexiones entre los edificios se han convertido en paseos, la explanada de los lixiviaderos en una pradera de pícnic y una escombrera en un sendero campestre. A ello se añaden inserciones puntuales: un molino de viento que es también un mirador hacia el panorama, unas gradas semicirculares que sirven como teatro al aire libre. Siguiendo el proyecto de Peter Latz (Weilacher 2008: 102ss.), el complejo industrial se ha convertido en un parque público en el que se integran buena parte de las viejas instalaciones -entendidas no tanto como monumento cuanto como objeto de experiencia-, se mantienen los ecosistemas generados espontáneamente en los años transcurridos después de su cierre y se recuperan en parte los preexistentes, mezclando la naturaleza selvática con los testimonios del mundo industrial y los usos recreativos y culturales del presente.

\section{De la artelización a la integración}

Centrales hidroeléctricas y minas a cielo abierto suponen la desaparición fisica de poblaciones y campos. Por su parte, las torres de refrigeración de las centrales nucleares, las chimeneas de las centrales térmicas y de las refinerías de petróleo, coronadas por penachos de humo, dominan el paisaje a veces de modo impresionante, pero son el signo indeleble de los residuos contaminantes arrojados al medio y de los riesgos inherentes a ellas. En cambio, las instalaciones de energías alternativas tienen connotaciones positivas y no despiertan un rechazo manifiesto como las anteriores, aunque presenten no pocos inconvenientes locales. Todas modifican el paisaje, a veces de manera brutal o invasiva, a veces puntual o difusa, pero no forzosamente de modo negativo si se hacen las previsiones oportunas.

Ahora bien, como al principio apuntábamos, la conciencia de los riesgos que algu- 
nas presentan, de los cambios sin vuelta atrás en ciertos casos y de la degradación visual y ambiental del hábitat que su presencia implica, ha dado lugar al llamado sindrome NIMBY, acrónimo de 'not in my backyard', que podría traducirse por 'cerca de mi casa no'. Esta expresión significa el rechazo a que ciertas instalaciones, reconocidas como social o económicamente necesarias, se sitúen en las proximidades de las áreas habitadas, lo que puede interpretarse de modo ambivalente: como falta de responsabilidad social por parte de los ciudadanos o como exigencia de protección de los entornos habitados.

Al contrario de lo que evasivamente se tiende a pensar, el problema de estos paisajes alterados -cuando no degradadospara explotar los recursos de un territorio, no suele residir en el rechazo popular a la proximidad de las instalaciones por un prejuicio injustificado. En lo que aquí nos atañe, reside en la falta de integración en su entorno -sea con medidas de restitución, de protección o de creación- que debería plantearse siempre como un objetivo esencial. No se trata de mantener el ideal de un paisaje arcádico, pero el problema no puede centrarse en mejorar la imagen pública de las empresas fabriles, energéticas o mineras mediante lo que podríamos llamar artelización publicitaria. Recordemos que la forma del paisaje recoge, asume y manifiesta los intereses culturales de una sociedad: banalizar su fealdad equivale a trivializar el descrédito de la propia cultura. Por tanto, la cuestión principal es lograr que las instalaciones industriales tengan un buen grado de adaptación a su entorno (figura 40); lo que en términos perceptivos implica no una ocultación, sino una transformación del paisaje que pueda ser entendida como positiva por la población. Para lo cual la planificación paisajistica resulta indispensable.

\section{Notas}

1. Artelización 'in situ' e 'in visu' son los términos empleados por Roger. Nos parece fonéticamente más apropiado traducir el vocablo francés 'artialisation' por 'artelización' en vez de 'artealización', como se ha propuesto. Para el paso de país a paisaje y su relación con la pintura, véase también Caro Baroja 1981: 13ss.

2. $\quad \mathrm{M}^{\mathrm{a}}$ Emilia Hernández Pezzi (2013: 36s.) lo ha recuperado para referirse a aquellos edificios contemporáneos en los que intencionadamente se prescinde de establecer vínculos con el entorno, renunciando a su capacidad para caracterizar el lugar y negando cualquier encuadre paisajístico.

3. Un ejemplo de ello producido por la acción de la naturaleza serian los llamados 'malpaíses'.

4. Con técnicas como la biorremediación o la fitorremediación, cuya finalidad es acelerar proce- sos que la naturaleza haría por sí misma en un período de tiempo más largo.

5. ZEPA: zona de especial protección de aves; ZEC: zona de especial conservación. Ambas son figuras de protección de la Red Natura 2000 de la Unión Europea.

6. En 2008 la compañía eléctrica de Islandia, Landsnet, convocó un concurso al que se presentaron propuestas como las de los equipos Arphenotype, en materiales ligeros, y Choi+Shine, en acero, con figuras que van variando a lo largo del tendido.

\section{Bibliografia}

Albelda, José. 2013-14. Los paisajes del declive: La concepción del paisaje en el contexto de la crisis ecológica global. Fabrikart 11: 12-27.

Berque, Augustin. 1995. Les raisons du paysage. De la Chine antique aux environnement de synthèse. Paris: Hazan.

Berque, Augustin. 2009. El pensamiento paisajero. Madrid: Biblioteca Nueva.

Burke, Edmund. 1985. Indagación filosófica sobre el origen de nuestras ideas acerca de la Sublime y lo Bello (1757). Murcia: Colegio Oficial de Aparejadores y Arquitectos Técnicos de Murcia y otros.

Caro Baroja, Julio. 1981. Paisajes y ciudades, Madrid: Taurus.

Hernández Pezzi, M $^{\mathrm{a}}$ Emilia. 2013. Paisaje/Despaisaje. En: Martinez-Medina, Andrés, Martínez Boix, Tomás y Banyuls i Pérez, Antoni (eds.), Otra arquitectura, otro paisaje. Alicante: Colegio Territorial de Arquitectos de Alicante. 31-42.

Martínez de Pisón, Eduardo. 2007. Paisaje, cultura y territorio. En: Nogué, Joan (ed.), La construcción social del paisaje. Madrid: Biblioteca Nueva. 325-337.

Price, Uvedale. 1971. Essays on the Picturesque, vol. I (1810). Farnborough: Gregg International Publishers.

Roger, Alain. 2007. Breve tratado del paisaje (1997). Madrid: Biblioteca Nueva.

Smithson, Robert. 2006. Un recorrido por los monumentos de Passaic, Nueva Jersey (1967). Barcelona: Gustavo Gili.

Spens, Michael. 1994. The Complete Lanscape Designs and Gardens of Geoffrey Jellicoe. Londres: Thames \& Hudson.

Watsuji, Tetsuro. 2006. Antropología del paisaje (1935). Salamanca: Sígueme.

Weilacher, Udo. 2008. Syntax of Landscape. The Landscape Architecture of Peter Latz and Partners. Basilea: Birckhäuser.

\section{Referencias de imágenes}

Ref. web 1:

https://commons.wikimedia.org/wiki/File:Gasp ard_Dughet_-_Landschap.jpg (acceso 20 abril 2016)

Ref. web 2:

https://commons.wikimedia.org/wiki/File:Toka ido45_Shono.jpg (acceso 21 abril 2016)

Ref. web 3:

https://www.google.es/maps/@44.7209733,11. $1559713,6084 \mathrm{~m} /$ data $=! 3 \mathrm{~m} 1 ! 1 \mathrm{e} 3$ (acceso 17 abril 2016)

Ref. web 4:

https://en.wikipedia.org/wiki/Salginatobel_Bri dge (acceso 12 abril 2016)

Ref. web 5:

http:/ / www.museoreinasofia.es/coleccion/obra /sarah (acceso 21 abril 2016)

Ref. web 6:

http: / / aquellaeme.blogspot.com.es/2015/08/q

ue-es-el-cine-moderno.html (acceso 21 abril

2016) 
Ref. web 7:

http:/ / www.bussolacultural.com/wp-

content/uploads/2015/05/sebastiao-

salgado_serra-pelada.jpg (acceso 14 abril 2016)

Ref. web 8: https://agoraformation.files.word-

press.com/2015/10/zinit-vue-gc3a9nc3a9rale-

avril-2007.jpg

(acceso 20 abril 2016)

Ref. web 9:

https://es.wikipedia.org/wiki/El_buey_desolla-

do (acceso 14 abril 2016)

Ref. web 10:

http:/ /ibytes.es/images/content/postimages/P owerFuegoTS/Incendio_Lagoa.jpg (acceso 21

abril 2016)

Ref. web 11: http://barzaj-

jan.blogspot.com.es/2013/05/naufragios.html (acceso 23 abril 2016)

Ref.web 12:

https://commons.wikimedia.org/wiki/Category: Rievaulx_Abbey\#/media/File:Riveaulx_abbey_in _tal.jpg (acceso 23 abril 2016)

Ref. web 13: http://colbyjennings.com/monuments-passaic-missouri/ (acceso 15 abril 2016) Ref. web 14:

http:/ / www.turisbox.com/?p=6805 (acceso 13 abril 2016)

Ref. web 15: http://www.endesa.com/es/saladeprensa/multimedia/imagenes/home (acceso 10 enero 2014)

Ref. web 16:

https://upload.wikimedia.org/wikipedia/commons/2/2a/Garzweiler_Tagebau_2008_-_2.jpg (acceso 14 abril 2016)

Ref. web 17: http://www.minasdesierramore-

na.es/wp-

content/uploads/08130710001_43.jpg (acceso 16 abril 2016)

Ref. web 18:

https://es.wikipedia.org/wiki/Anexo:Centrales_ t\%C3\%A9rmicas_en_Espa\%C3\%B1a\#/media/Fi le:TermicaLaRobla.jpg (acceso 21 abril 2016) Ref. web 19:

http://www.panoramio.com/photo_explorer\#vie $\mathrm{w}=$ photo\&position=218\&with_photo_id=100916 $12 \&$ order=date_desc\&user $=1711041$ (acceso 20 abril 2016)

Ref. web 20:

https://opinionateddesigner.files.wordpress.co m/2015/09/piantastabilimento.jpg (acceso 23 abril 2016)

Ref. web 21: http://www.ecoclimatico.com/wpcontent/uploads /2008/12/planta-fotovoltaicaamareleja-moura.jpg (acceso 21 abril 2016) Ref. web 22:

http:/ / estatico.vozpopuli.com/upload/Mario_Sa nchez/sanlucar.jpg (acceso 21 abril 2016) Ref. web 23:

http://www.magrama.gob.es/es/desarrollorural/temas / caminos-naturales / 18-03_tcm7160920.jpg (acceso 18 abril 2016) 